\title{
Microwave-Assisted Synthesis of Chalcopyrite/Silver Phosphate Composites with Enhanced Degradation of Rhodamine B under Photo-Fenton Process
}

\author{
Shun-An Chang ${ }^{1}$, Po-Yu Wen ${ }^{1}$, Tsunghsueh Wu ${ }^{2, *}$ and Yang-Wei Lin ${ }^{1, * \mathbb{D}}$ \\ 1 Department of Chemistry, National Changhua University of Education, 1 Jin-De road, \\ Changhua City 50007, Taiwan; jack5566yes@gmail.com (S.-A.C.); bba02123@gmail.com (P.-Y.W.) \\ 2 Department of Chemistry, University of Wisconsin-Platteville, 1 University Plaza, \\ Platteville, WI 53818-3099, USA \\ * Correspondence: wut@uwplatt.edu (T.W.); linywjerry@cc.ncue.edu.tw (Y.-W.L.); \\ Tel.: +1-608-342-6018 (T.W.); +886-4-7232105-3553 (Y.-W.L.)
}

Received: 23 October 2020; Accepted: 18 November 2020; Published: 20 November 2020

check for updates

\begin{abstract}
A new composite by coupling chalcopyrite $\left(\mathrm{CuFeS}_{2}\right)$ with silver phosphate $\left(\mathrm{Ag}_{3} \mathrm{PO}_{4}\right)$ $\left(\mathrm{CuFeS}_{2} / \mathrm{Ag}_{3} \mathrm{PO}_{4}\right)$ was proposed by using a cyclic microwave heating method. The prepared composites were characterized by scanning and transmission electron microscopy and $\mathrm{X}$-ray diffraction, Fourier-transform infrared, UV-Vis diffuse reflectance spectroscopy, and X-ray photoelectron spectroscopy. Under optimum conditions and $2.5 \mathrm{~W}$ irradiation (wavelength length $>420 \mathrm{~nm}$, power density $\left.=0.38 \mathrm{Wcm}^{-2}\right), 96 \%$ of rhodamine $\mathrm{B}(\mathrm{RhB})$ was degraded by $\mathrm{CuFeS}_{2} / \mathrm{Ag}_{3} \mathrm{PO}_{4}$ within a 1 min photo-Fenton reaction, better than the performance of $\mathrm{Ag}_{3} \mathrm{PO}_{4}(25 \%$ degradation within $10 \mathrm{~min}), \mathrm{CuFeS}_{2}(87.7 \%$ degradation within $1 \mathrm{~min})$, and mechanically mixed $\mathrm{CuFeS}_{2} / \mathrm{Ag}_{3} \mathrm{PO}_{4}$ catalyst. $\mathrm{RhB}$ degradation mainly depended on the amount of hydroxyl radicals generated from the Fenton reaction. The degradation mechanism of $\mathrm{CuFeS}_{2} / \mathrm{Ag}_{3} \mathrm{PO}_{4}$ from the photo-Fenton reaction was deduced using a free radical trapping experiment, the chemical reaction of coumarin, and photocurrent and luminescence response. The incorporation of $\mathrm{CuFeS}_{2}$ in $\mathrm{Ag}_{3} \mathrm{PO}_{4}$ enhanced the charge separation of $\mathrm{Ag}_{3} \mathrm{PO}_{4}$ and reduced $\mathrm{Ag}_{3} \mathrm{PO}_{4}$ photocorrosion as the photogenerated electrons on $\mathrm{Ag}_{3} \mathrm{PO}_{4}$ were transferred to regenerate $\mathrm{Cu}^{2+} / \mathrm{Fe}^{3+}$ ions produced from the Fenton reaction to $\mathrm{Cu}^{+} / \mathrm{Fe}^{2+}$ ions, thus simultaneously maintaining the $\mathrm{CuFeS}_{2}$ intact. This demonstrates the synergistic effect on material stability. However, hydroxyl radicals were produced by both the photogenerated holes of $\mathrm{Ag}_{3} \mathrm{PO}_{4}$ and the Fenton reaction of $\mathrm{CuFeS}_{2}$ as another synergistic effect in catalysis. Notably, the degradation performance and the reusability of $\mathrm{CuFeS}_{2} / \mathrm{Ag}_{3} \mathrm{PO}_{4}$ were promoted. The practical applications of this new material were demonstrated from the effective performance of $\mathrm{CuFeS}_{2} / \mathrm{Ag}_{3} \mathrm{PO}_{4}$ composites in degrading various dyestuffs (90-98.9\% degradation within $10 \mathrm{~min}$ ) and dyes in environmental water samples (tap water, river water, pond water, seawater, treated wastewater) through enhanced the Fenton reaction under sunlight irradiation.
\end{abstract}

Keywords: $\mathrm{CuFeS}_{2} / \mathrm{Ag}_{3} \mathrm{PO}_{4} ;$ Fenton process; degradation; sunlight; environmental water samples

\section{Introduction}

Recently, concerns have been raised worldwide toward the harm caused by residual organic pollutants in surface water and groundwater, threatening ecosystems and aquatic species [1-3]. Among the many sources of water pollution, wastewater from the printing and dyeing industry is a major concern. The decolorization and degradation of most chromophores in dyes are difficult because of their stable aromatic structures, leading to prolonged toxic effects and environmental hazards [4-6]. Furthermore, dyes can absorb sunlight and reduce water clarity, preventing photosynthesis in 
aquatic plants, decreasing dissolved oxygen in water, affecting microbial diversity, and disrupting the self-purification capacity of water [7]. The removal of these deleterious and hazardous pollutants from industrial wastewater has become an urgent environmental need in the world [8].

Many studies have evaluated the removal of organic dyes by using photocatalytic degradation, ideally using sunlight, with the vision of sustainable water treatment. $\mathrm{TiO}_{2}$ is the most widely used photocatalytic semiconductor because of its nontoxic and stable nature, with a relatively low cost and abundant production resulting from a mature manufacturing process $[9,10]$. However, its absorption and photocatalytic activity depends entirely on ultraviolet light, which restricts its application in large-scale wastewater treatment [11-13]. Studies have been attempting to identify efficient sunlight-responsive photocatalysts, and $\mathrm{Ag}_{3} \mathrm{PO}_{4}$, with a quantum efficiency of $>90 \%$, is considered an excellent candidate that is sunlight responsive [14-16]. However, it experiences considerable photocorrosion during photolysis. In addition to the photocatalytic method, $\mathrm{Cu} / \mathrm{Fe}$-bearing solids such as chalcopyrite $\left(\mathrm{CuFeS}_{2}\right)$ have been widely used as catalysts in advanced oxidation processes (AOPs) for wastewater treatment [17-21]. In general, AOPs are based on Fenton's chemistry, which utilizes hydroxyl radicals produced from the Fenton reaction between $\mathrm{H}_{2} \mathrm{O}_{2}$ and $\mathrm{Cu}^{+} / \mathrm{Fe}^{2+}$ ions to degrade organic dyes (Equations (1)-(6)) [22,23]. However, the reusability of $\mathrm{CuFeS}_{2}$ is a challenge due to its dissolution during water treatment and the slow kinetics of $\mathrm{Fe}^{2+}$ regeneration:

$$
\begin{aligned}
& \mathrm{CuFeS}_{2}(\mathrm{~s})+8 \mathrm{H}_{2} \mathrm{O}_{2} \rightarrow \mathrm{Fe}^{3+}+\mathrm{Cu}^{2+}+2 \mathrm{SO}_{4}{ }^{2-}+8 \mathrm{H}_{2} \mathrm{O}+2 \mathrm{H}^{+} \\
& \mathrm{CuFeS}_{2}(\mathrm{~s})+16 \mathrm{Fe}^{3+}+8 \mathrm{H}_{2} \mathrm{O} \rightarrow 17 \mathrm{Fe}^{2+}+\mathrm{Cu}^{2+}+2 \mathrm{SO}_{4}{ }^{2-}+16 \mathrm{H}^{+} \\
& \mathrm{CuFeS}_{2}(\mathrm{~s})+4 \mathrm{O}_{2} \rightarrow \mathrm{Fe}^{2+}+\mathrm{Cu}^{2+}+2 \mathrm{SO}_{4}{ }^{2-} \\
& \mathrm{Fe}^{2+}+\mathrm{H}_{2} \mathrm{O}_{2} \rightarrow \mathrm{Fe}^{3+}+\mathrm{OH}^{-}+\mathrm{OH} \cdot \\
& \mathrm{Cu}^{2+}+\mathrm{H}_{2} \mathrm{O}_{2} \rightarrow \mathrm{Cu}^{+}+\mathrm{O}_{2}{ }^{-}+2 \mathrm{H}^{+} \\
& \mathrm{Cu}^{+}+\mathrm{H}_{2} \mathrm{O}_{2} \rightarrow \mathrm{Cu}^{2+}+\mathrm{OH}^{-}+\mathrm{OH} \cdot \\
& \mathrm{Fe}^{3+}+\mathrm{H}_{2} \mathrm{O} \rightarrow \mathrm{Fe}(\mathrm{OH})^{2+}+\mathrm{H}^{+} \\
& \mathrm{Fe}(\mathrm{OH})^{2+}+\mathrm{h} v \rightarrow \mathrm{Fe}^{2+}+\mathrm{OH} .
\end{aligned}
$$

To address $\mathrm{CuFeS}_{2}$ reusability, attempts have been made to regenerate the Fenton catalysts with UV and/or visible-light irradiation, known as the photo-Fenton process [19,24,25]. Under UV and/or visible-light irradiation, $\mathrm{Fe}^{3+}$ complexes are formed from the Fenton reaction (Equation (7)) to produce both $\mathrm{Fe}^{2+}$ and hydroxyl radicals (Equation (8)). The photogenerated $\mathrm{Fe}^{2+}$ ions can catalyze the Fenton reaction to form $\mathrm{Fe}^{3+}$, thus demonstrating the recyclability of Fenton catalysts (Equation (4)). For instance, Dotto et al. demonstrated that the prepared citrate- $\mathrm{CuFeS}_{2}$ materials possessed $90 \%$ catalytic efficiency for bisphenol A (BPA) degradation with a $15 \mathrm{~min}$ photo-Fenton process for its rapid generation of hydroxyl radicals and efficient $\mathrm{H}_{2} \mathrm{O}_{2}$ consumption [24]. Dotto et al. also reported that the catalytic efficiency and stability was sustained after four consecutive photoregeneration cycles. However, the preparation of the novel $\mathrm{CuFeS}_{2}$ samples requires a high power and expensive microwave reactor $\left(1400 \mathrm{~W}, 200^{\circ} \mathrm{C}, 7 \mathrm{~min}\right)$. In another simpler attempt in material preparation, Pastrana-Martinez et al. used the mineral of $\mathrm{CuFeS}_{2}$ mined from Jendouba, Tunisia, to catalyze tyrosol (TY) degradation by using a UV light-emitting diode (LED)-assisted photo-Fenton reaction [19]. Higher total organic carbon (TOC) conversions $(85.0 \%)$ and lower iron leaching $\left(0.89 \mathrm{mg} \cdot \mathrm{L}^{-1}\right)$ were attained when the purified $\mathrm{CuFeS}_{2}$ samples were used in the photo-Fenton-like process within $60 \mathrm{~min}(0.50 \mathrm{mM}$ TY at stoichiometric $\mathrm{H}_{2} \mathrm{O}_{2}$ concentrations). However, UV light irradiation is not considered sustainable because it requires a high energy input. The limitations of the methods used in all these studies underline the need to improve the visible-light absorption ability and efficiently boost the degradation performance and stability of $\mathrm{CuFeS}_{2}$. To our knowledge, $\mathrm{CuFeS}_{2}$ coupled with other semiconductors has not been examined in the Fenton process under visible-light irradiation. 
Here, we synthesized $\mathrm{CuFeS}_{2}$ coupled with $\mathrm{Ag}_{3} \mathrm{PO}_{4}\left(\mathrm{CuFeS}_{2} / \mathrm{Ag}_{3} \mathrm{PO}_{4}\right)$ through cyclic microwave heating to address the challenges in material preparation, the stability of materials, and degradation performance. The breakthrough in our synthesis is that $\mathrm{CuFeS} 2 / \mathrm{Ag}_{3} \mathrm{PO}_{4}$ could be prepared using a domestic $336 \mathrm{~W}$ microwave oven within $12 \mathrm{~min}$. Our previous report indicated that $\mathrm{Ag}_{3} \mathrm{PO}_{4}$ is an efficient photocatalyst responsive to visible light and sunlight, so incorporating $\mathrm{Ag}_{3} \mathrm{PO}_{4}$ into the $\mathrm{CuFeS}_{2}$ Fenton reaction system might greatly increase the visible-light absorption while improving the regeneration of $\mathrm{Fe}^{2+} / \mathrm{Cu}^{+}$ions. Here, we used $\mathrm{CuFeS} 2 / \mathrm{Ag}_{3} \mathrm{PO}_{4}$ composites for the degradation of organic dyes (rhodamine $\mathrm{B}(\mathrm{RhB})$, methyl red (MR), rhodamine 6G (R6G), fluorescein, and propidium iodide (PI)). We also proposed that the degradation mechanism of $\mathrm{CuFeS}_{2} / \mathrm{Ag}_{3} \mathrm{PO}_{4}$ and the reactive species and successfully demonstrated the regeneration of the $\mathrm{CuFeS}_{2}$ catalyst and the application of $\mathrm{CuFeS}_{2} / \mathrm{Ag}_{3} \mathrm{PO}_{4}$ in the treatment of environmental samples.

\section{Materials and Methods}

\subsection{Preparation of $\mathrm{Ag}_{3} \mathrm{PO}_{4}, \mathrm{CuFeS}$, and $\mathrm{CuFeS} 2 / \mathrm{Ag}_{3} \mathrm{PO}_{4}$}

All chemicals were purchased from Sigma Aldrich (St. Louis, MO, USA) and were of analytical grade and thus used without further purification. First, $0.212 \mathrm{~g}$ of $\mathrm{AgNO}_{3}$ was added to $20 \mathrm{~mL}$ of deionized water $(18.2 \mathrm{M} \Omega \cdot \mathrm{cm})$ with stirring. Then, a colorless $\mathrm{Ag}\left(\mathrm{NH}_{3}\right)_{2}{ }^{+}$ion solution was produced by adding $6.2 \mathrm{~mL}$ of $14 \mathrm{M} \mathrm{NH}_{3}$ solution dropwise into the $\mathrm{AgNO}_{3}$ solution. After 30 min stirring, $3.5 \mathrm{~mL}$ of $\mathrm{H}_{3} \mathrm{PO}_{4}(14.6 \mathrm{M})$ was used to neutralize the mixed solution to $\mathrm{pH} 7.0$, and the solution was stirred again for $30 \mathrm{~min}$ in the dark. The yellow precipitate was filtered and subsequently rinsed with copies of deionized water and anhydrous ethanol. Finally, the as-synthesized $\mathrm{Ag}_{3} \mathrm{PO}_{4}$ was dried at $55^{\circ} \mathrm{C}$ for $12 \mathrm{~h} \mathrm{[26].}$

$\mathrm{CuFeS}_{2}$ was prepared using the cyclic microwave heating method [27]. First, $19.7 \mathrm{mg}$ of $\mathrm{CuCl}$, $25.35 \mathrm{mg}$ of $\mathrm{FeCl}_{3}$, and $48.46 \mathrm{mg}$ of L-cysteine were added to $20 \mathrm{~mL}$ of deionized water with stirring for $15 \mathrm{~min}$. Then, the mixed solution underwent 10 cycles of $36 \mathrm{~s}$ heating and a $36 \mathrm{~s}$ pause in a domestic microwave oven (power: $336 \mathrm{~W}$ ). After the black precipitate was cooled to room temperature, it was rinsed with deionized water and anhydrous ethanol. Finally, the as-synthesized $\mathrm{CuFeS}_{2}$ was dried at $55{ }^{\circ} \mathrm{C}$ for $12 \mathrm{~h}$. $\mathrm{Cu}_{2} \mathrm{~S}$ and $\mathrm{Fe}_{2} \mathrm{~S}_{3}$ were prepared following similar method without adding $\mathrm{FeCl}_{3}$ and $\mathrm{CuCl}$ precursor, respectively. The $\mathrm{CuFeS} / \mathrm{Ag}_{3} \mathrm{PO}_{4}$ with a molar ratio of 2.5:1 was prepared as followed: $20 \mathrm{mg}$ of $\mathrm{Ag}_{3} \mathrm{PO}_{4}, 19.7 \mathrm{mg}$ of $\mathrm{CuCl}, 25.35 \mathrm{mg}$ of $\mathrm{FeCl}_{3}$, and $48.46 \mathrm{mg}$ of L-cysteine were added to $20 \mathrm{~mL}$ of deionized water with stirring for $15 \mathrm{~min}$. Then, the mixed solution underwent 10 cycles of $36 \mathrm{~s}$ heating and a $36 \mathrm{~s}$ pause in a domestic microwave oven (power: $336 \mathrm{~W}$ ). After the black precipitate was cooled to room temperature, it was rinsed with deionized water and anhydrous ethanol. Finally, the prepared $\mathrm{CuFeS}_{2} / \mathrm{Ag}_{3} \mathrm{PO}_{4}$ was dried at $55^{\circ} \mathrm{C}$ for $12 \mathrm{~h}$ and the weight of $\mathrm{CuFeS} / \mathrm{Ag}_{3} \mathrm{PO}_{4}$ was $41.7 \mathrm{mg}$. Thus, the weight percentage of $\mathrm{CuFeS}_{2}$ in $\mathrm{CuFeS}_{2} / \mathrm{Ag}_{3} \mathrm{PO}_{4}$ was $52 \%$. In this condition, we estimated the weight of $\mathrm{CuFeS}_{2}$ and $\mathrm{Ag}_{3} \mathrm{PO}_{4}$ in the $\mathrm{CuFeS}_{2} / \mathrm{Ag}_{3} \mathrm{PO}_{4}$ was $21.7 \mathrm{mg}$ and $20 \mathrm{mg}$, respectively. Therefore, the molar ratio of $\mathrm{CuFeS}_{2} / \mathrm{Ag}_{3} \mathrm{PO}_{4}$ was calculated to be 2.5:1 [27]. In addition, the preparation of $\mathrm{CuFeS}_{2} / \mathrm{Ag}_{3} \mathrm{PO}_{4}$ with different molar ratios (0.4:1 and 1:1) followed the same method and was prepared by decreasing the adding amounts of $\mathrm{CuCl}$ and $\mathrm{FeCl}_{3}$ precursors at $20 \mathrm{mg} \mathrm{Ag}_{3} \mathrm{PO}_{4}$.

\subsection{Characterization of $\mathrm{Ag}_{3} \mathrm{PO}_{4}, \mathrm{CuFeS}$, and $\mathrm{CuFeS} 2 / \mathrm{Ag}_{3} \mathrm{PO}_{4}$}

The morphological and compositional characteristics of all as-prepared samples were observed with scanning electron microscopy (SEM) on a HITACHIS-4300 (Hitachi, Tokyo, Japan) and transmission electron microscopy (TEM) on a 1200EX II (JEOL, Tokyo, Japan) equipped with a QUANTAX Annular XFlash QUAD FQ5060 (Bruker Nano, Berlin, Germany). The crystallographic texture of the samples was measured through powder X-ray diffraction (XRD) on SMART APEX II (Bruker AXS, Billerica, MA, USA) using $\mathrm{Cu} \mathrm{K} \alpha$ radiation $(\lambda=1.5406 \AA$ ). Fourier-transform infrared (FT-IR) spectra were obtained using an Agilent Cary 600 FT-IR spectrometer (Agilent Technologies, Santa Clara, CA, USA). An Evolution 2000UV-Vis spectrophotometer (Thermo Fisher Scientific Inc., Madison, WI, USA) 
with integrating spheres and reflectance standard material $\mathrm{BaSO}_{4}$ was applied to obtain the UV-Vis diffuse reflectance spectroscopy (DRS). The binding energy of elements was determined through X-ray photoelectron spectroscopy (XPS) on a VG ESCA210 (VG Scientific, West Sussex, UK).

\subsection{Degradation Procedure by Using $\mathrm{Ag}_{3} \mathrm{PO}_{4}, \mathrm{CuFeS}$, and $\mathrm{CuFeS} / \mathrm{Ag}_{3} \mathrm{PO}_{4}$}

RhB degradation was used to assess the degradation activity of the prepared samples. The photoreactor PCX-50C (Beijing Perfectlight Technology Co. Ltd., Beijing, China) was equipped with a low-power white LED irradiation $\left(2.5 \mathrm{~W}\right.$, power density $=0.38 \mathrm{~W} \cdot \mathrm{cm}^{-2}$, wavelength $\left.>420 \mathrm{~nm}\right)$. For the photo-Fenton reaction, $20 \mathrm{mg}$ of the prepared catalyst samples was added into the RhB solution ( $20 \mathrm{ppm}, 50 \mathrm{~mL}$ ), and the solution was stirred in the dark for $30 \mathrm{~min}$. Before $10 \mathrm{~min}$, to turn the light on and add $\mathrm{H}_{2} \mathrm{O}_{2}$, we measured the absorbance to check the adsorption ability of the prepared samples. Subsequently, the LED lamp was turned on and $200 \mu \mathrm{L}$ of $\mathrm{H}_{2} \mathrm{O}_{2}(35 \%)$ was added. After given time intervals, $1 \mathrm{~mL}$ of suspension was taken, quenched immediately by adding $0.1 \mathrm{mM} \mathrm{NaN}_{3}$ and filtered by a $0.22 \mu \mathrm{m}$ syringe filter organic membrane to remove the catalyst sample. The concentration of RhB was measured using a Synergy $\mathrm{H} 1$ hybrid multimode microplate reader (BioTek Instruments, Winooski, VT, USA) at its characteristic absorption peak of $550 \mathrm{~nm}$. Similar processes were performed for other dyestuffs (MR, R6G, fluorescein, and PI). The RhB degradation $(20 \mathrm{ppm}, 50 \mathrm{~mL})$ for the photocatalytic and Fenton reactions was performed using the same protocols (20 mg catalysts) as mentioned above, but without the addition of $\mathrm{H}_{2} \mathrm{O}_{2}$ and LED light irradiation, respectively. After the experiment, TOC concentration was determined on an Elementar Acquray TOC analyzer (Elementar Analysensysteme $\mathrm{GmbH}$, Langenselbold, Germany) to evaluate the extent of mineralization.

\subsection{Evaluation of Charge Separation and Recombination Rate of $\mathrm{Ag}_{3} \mathrm{PO}_{4}, \mathrm{CuFeS}$, and $\mathrm{CuFeS} / \mathrm{Ag}_{3} \mathrm{PO}_{4}$}

The charge separation efficiency and recombination rate of electron-hole pairs for the prepared composites were evaluated according to our earlier reports [28-30]. Photocurrent was measured to evaluate the charge separation efficiency of $\mathrm{Ag}_{3} \mathrm{PO}_{4}, \mathrm{CuFeS}_{2}$, and $\mathrm{CuFeS} / \mathrm{Ag}_{3} \mathrm{PO}_{4}$ composites under constant white LED irradiation at $60 \mathrm{~s}$ intervals. To determine the recombination rate of electron-hole pairs, the photoluminescence (PL) spectra of samples were obtained using $\lambda_{\mathrm{ex}}=250 \mathrm{~nm}$ with a Varian Cary Eclipse fluorescence spectrophotometer (Agilent Technologies, Santa Clara, CA, USA).

\subsection{Free Radical Trapping Experiment of $\mathrm{Ag}_{3} \mathrm{PO}_{4}, \mathrm{CuFeS}_{2}$, and $\mathrm{CuFeS} \mathrm{S}_{2} / \mathrm{Ag}_{3} \mathrm{PO}_{4}$}

To investigate the active species generated during $\mathrm{RhB}$ degradation over $\mathrm{Ag}_{3} \mathrm{PO}_{4}, \mathrm{CuFeS}_{2}$, and $\mathrm{CuFeS} / \mathrm{Ag}_{3} \mathrm{PO}_{4}$, the trapping experiment was conducted using ethylenediaminetetraacetate (EDTA), tert-butanol (t-BuOH), and p-benzoquinone $(\mathrm{BQ})($ each $1 \mathrm{mM}$ ) as the capturing agent for holes, hydroxyl radicals, and oxygen radicals, respectively. The implemented trapping experimental procedure was identical to the steps mentioned in the degradation section except for the capturing agent being added at each run.

\section{Results and Discussion}

\subsection{Morphology and Crystal Phase of $\mathrm{Ag}_{3} \mathrm{PO}_{4}, \mathrm{CuFeS}$, and $\mathrm{CuFeS} / \mathrm{Ag}_{3} \mathrm{PO}_{4}$}

The morphology of the prepared $\mathrm{Ag}_{3} \mathrm{PO}_{4}, \mathrm{CuFeS}_{2}$, and $\mathrm{CuFeS}_{2} / \mathrm{Ag}_{3} \mathrm{PO}_{4}$ composites was analyzed through SEM and TEM (Figure 1). As shown in Figure 1, $\mathrm{Ag}_{3} \mathrm{PO}_{4}$ appears as tetrapod-like structures, with its four cylindrical arms being approximately 7-10 $\mu \mathrm{m}$ in length and with its average diameter being 2-3 $\mu \mathrm{m}$. The $\mathrm{CuFeS}_{2}$ crystals appear irregular and sheet-like with sizes of $0.2-2 \mu \mathrm{m}$. As for the prepared $\mathrm{Ag}_{3} \mathrm{PO}_{4} / \mathrm{CuFeS}_{2}$ composites, $\mathrm{CuFeS}_{2}$ sheets were randomly deposited on the $\mathrm{Ag}_{3} \mathrm{PO}_{4}$ surface, and this deposition has no effect on the morphology and chemical composition of the $\mathrm{Ag}_{3} \mathrm{PO}_{4}$ particles. The corresponding magnified TEM image revealed clear lattice fringes with a $\mathrm{d}$ spacing of 0.249 and $0.312 \mathrm{~nm}$, which are in good agreement with the (210) and (112) lattice planes of $\mathrm{Ag}_{3} \mathrm{PO}_{4}$ and $\mathrm{CuFeS}_{2}$, respectively. The energy dispersive spectrometer (EDS) spectra of the prepared $\mathrm{Ag}_{3} \mathrm{PO}_{4}$, 
$\mathrm{CuFeS}_{2}$, and $\mathrm{CuFeS}_{2} / \mathrm{Ag}_{3} \mathrm{PO}_{4}$ composites (Figure 2) confirm the presence of $\mathrm{Ag}, \mathrm{P}, \mathrm{O}, \mathrm{Cu}, \mathrm{Fe}$, and $\mathrm{S}$ elements in their crystals accordingly. In addition, we also found $\mathrm{C}$ element in the presence of $\mathrm{CuFeS}_{2}$ and $\mathrm{CuFeS} 2 / \mathrm{Ag}_{3} \mathrm{PO}_{4}$ composites. This is because we used L-cysteine precursor in the preparation of $\mathrm{CuFeS}_{2}$ and $\mathrm{CuFeS}_{2} / \mathrm{Ag}_{3} \mathrm{PO}_{4}$ composites.

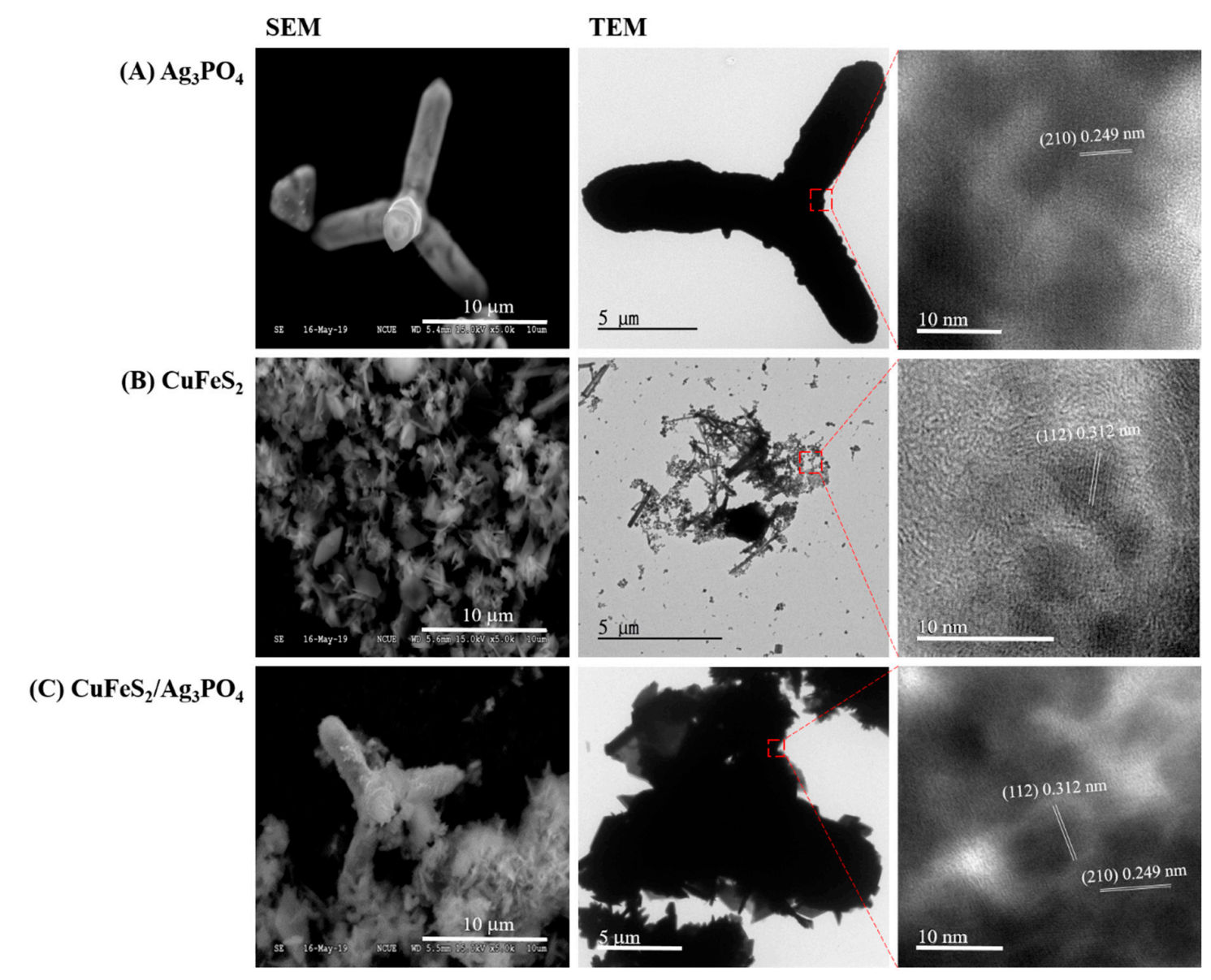

Figure 1. SEM and TEM images of (A) $\mathrm{Ag}_{3} \mathrm{PO}_{4} ;(\mathbf{B}) \mathrm{CuFeS}_{2}$; and (C) $\mathrm{CuFeS}_{2} / \mathrm{Ag}_{3} \mathrm{PO}_{4}$ composites.

The XRD spectra of the prepared $\mathrm{Ag}_{3} \mathrm{PO}_{4}, \mathrm{CuFeS}_{2}$, and $\mathrm{CuFeS} / \mathrm{Ag}_{3} \mathrm{PO}_{4}$ composites are displayed in Figure 3. From the black curve of $\mathrm{Ag}_{3} \mathrm{PO}_{4}$, the diffraction peaks at $21.5^{\circ}, 30.1^{\circ}, 33.4^{\circ}, 36.7^{\circ}, 42.5^{\circ}$, $48.7^{\circ}, 53.6^{\circ}, 55.3^{\circ}, 57.5^{\circ}, 62.4^{\circ}, 65.1^{\circ}, 70.7^{\circ}, 72.2^{\circ}, 74.6^{\circ}$, and $78.2^{\circ}$ were identified and assigned to the (110), (200), (210), (211), (220), (310), (222), (320), (321), (400), (330), (420), (421), (332), and (442) faces of the cubic $\mathrm{Ag}_{3} \mathrm{PO}_{4}$, respectively (JCPDS No. 06-0505) [26]. The XRD pattern of $\mathrm{CuFeS}_{2}$ is presented in the red curve of Figure 3 , and the diffraction peaks at $28.9^{\circ}, 46.4^{\circ}$, and $56.2^{\circ}$ corresponded well to the (112), (220), and (312) faces of the tetragonal chalcopyrite $\mathrm{CuFeS}_{2}$, respectively (JCPDS No. 01-0842) [27]. As a confirmation of good composite quality, the diffraction patterns of the prepared $\mathrm{CuFeS}_{2} / \mathrm{Ag}_{3} \mathrm{PO}_{4}$ composites match with the patterns of $\mathrm{Ag}_{3} \mathrm{PO}_{4}$ and $\mathrm{CuFeS}_{2}$. According to Scherer's equation, the average crystallite size of $\mathrm{Ag}_{3} \mathrm{PO}_{4}$ and $\mathrm{CuFeS}_{2}$ was 55.8 and $43.5 \mathrm{~nm}$, respectively. In addition, they did not change in the $\mathrm{CuFeS}_{2} / \mathrm{Ag}_{3} \mathrm{PO}_{4}$ composites $\left(\mathrm{Ag}_{3} \mathrm{PO}_{4}: 57.0 \mathrm{~nm}, \mathrm{CuFeS}_{2}\right.$ : $46.5 \mathrm{~nm})$. 

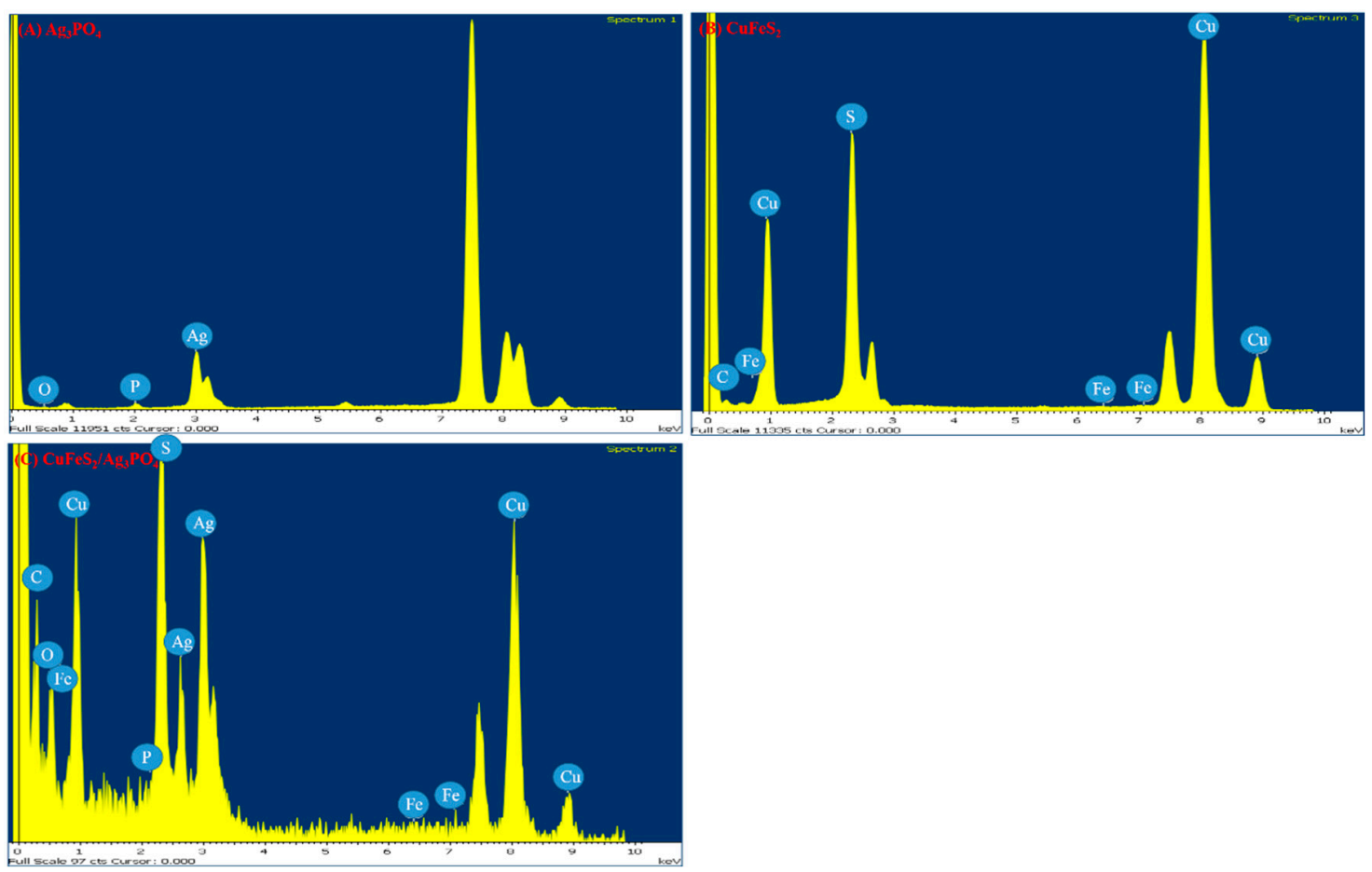

Figure 2. EDS spectra of (A) $\mathrm{Ag}_{3} \mathrm{PO}_{4} ;(\mathbf{B}) \mathrm{CuFeS}_{2}$; and (C) $\mathrm{CuFeS}_{2} / \mathrm{Ag}_{3} \mathrm{PO}_{4}$ composites.

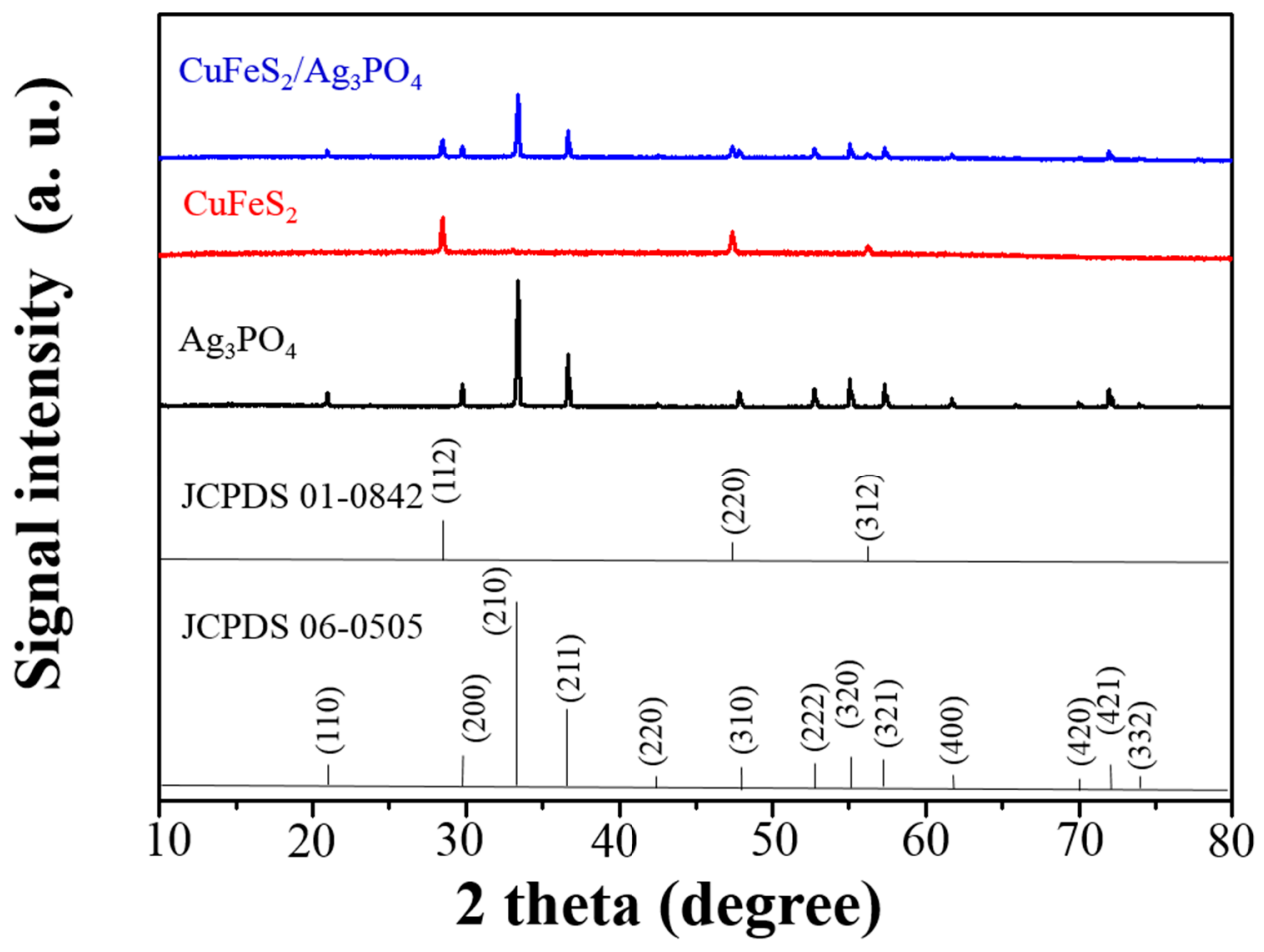

Figure 3. XRD patterns of different samples: $\mathrm{Ag}_{3} \mathrm{PO}_{4}$ (black); $\mathrm{CuFeS}_{2}$ (red); and $\mathrm{CuFeS}_{2} / \mathrm{Ag}_{3} \mathrm{PO}_{4}$ composites (blue).

3.2. Optical Property of $\mathrm{Ag}_{3} \mathrm{PO}_{4}, \mathrm{CuFeS}$, and $\mathrm{CuFeS} \mathrm{S}_{2} / \mathrm{Ag}_{3} \mathrm{PO}_{4}$

The FT-IR spectra of the prepared $\mathrm{Ag}_{3} \mathrm{PO}_{4}, \mathrm{CuFeS}_{2}$, and $\mathrm{CuFeS}_{2} / \mathrm{Ag}_{3} \mathrm{PO}_{4}$ composites are shown in Figure 4. The IR spectrum for $\mathrm{Ag}_{3} \mathrm{PO}_{4}$ shows four major peaks located at 560, 1012, 1670, and $3200 \mathrm{~cm}^{-1}$, which corresponded to the $\mathrm{PO}_{4}{ }^{3-}$ stretching and $\mathrm{O}-\mathrm{H}$ bending vibration, respectively. 
The $\mathrm{O}-\mathrm{H}$ bending in the prepared $\mathrm{Ag}_{3} \mathrm{PO}_{4}$ may be attributed from $\mathrm{Ag}_{3} \mathrm{PO}_{4}$ adsorbed water from the air. For $\mathrm{CuFeS}_{2}$, it shows three peaks located at 1045, 1640, and $3400 \mathrm{~cm}^{-1}$, which corresponded to the $\mathrm{C}=\mathrm{S}$ stretching and $\mathrm{O}-\mathrm{H}$ bending vibration, respectively. The $\mathrm{O}-\mathrm{H}$ bending in the prepared $\mathrm{CuFeS}_{2}$ may be attributed from $\mathrm{CuFeS}_{2}$ adsorbed water from the air. The $\mathrm{C}=\mathrm{S}$ stretching in the prepared $\mathrm{CuFeS}_{2}$ may be attributed from the L-cysteine precursor. In addition, the EDS spectra for $\mathrm{CuFeS}_{2}$ and $\mathrm{CuFeS}_{2} / \mathrm{Ag}_{3} \mathrm{PO}_{4}$ composites also confirmed the presence of $\mathrm{C}$ element. For $\mathrm{CuFeS} / \mathrm{Ag}_{3} \mathrm{PO}_{4}$ composites, the spectrum exhibited $\mathrm{PO}_{4}{ }^{3-}, \mathrm{C}=\mathrm{S}$, and $\mathrm{O}-\mathrm{H}$ vibration peaks in the present on their crystals.

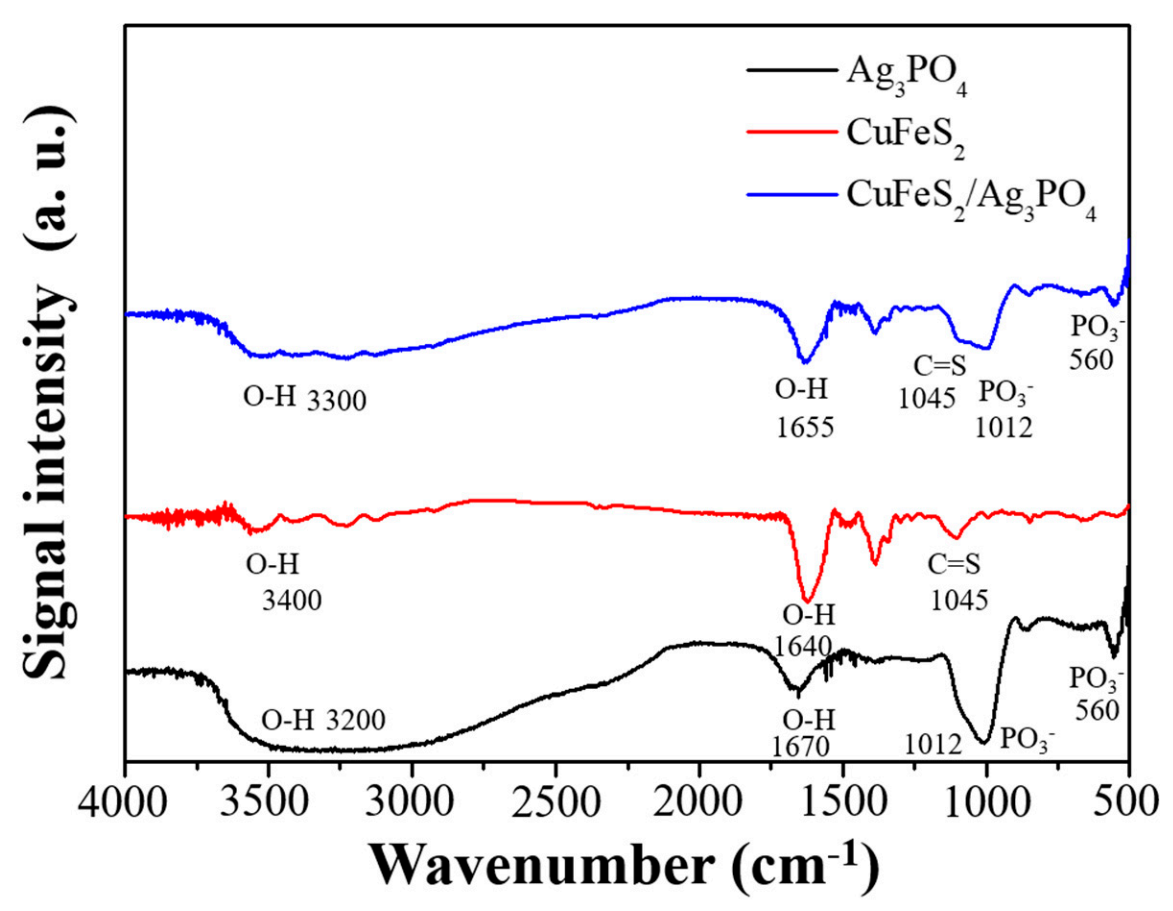

Figure 4. FT-IR spectra of different samples: $\mathrm{Ag}_{3} \mathrm{PO}_{4}$ (black); $\mathrm{CuFeS}_{2}$ (red); and $\mathrm{CuFeS}_{2} / \mathrm{Ag}_{3} \mathrm{PO}_{4}$ composites (blue).

To study the optical absorption characteristics of the prepared $\mathrm{Ag}_{3} \mathrm{PO}_{4}, \mathrm{CuFeS}_{2}$, and $\mathrm{CuFeS} / \mathrm{Ag}_{3} \mathrm{PO}_{4}$ composites, UV-Vis DRS was performed, as shown in Figure 5. The absorption band-edge for $\mathrm{Ag}_{3} \mathrm{PO}_{4}, \mathrm{CuFeS}$ and $\mathrm{CuFeS}_{2} / \mathrm{Ag}_{3} \mathrm{PO}_{4}$ is at approximately 525, 427, and $487 \mathrm{~nm}$, respectively. The bandgap energy (Eg) of $\mathrm{Ag}_{3} \mathrm{PO}_{4}$ is theoretically estimated to be $2.38 \mathrm{eV}$ using the equation $\alpha \mathrm{h} v=\mathrm{A}(\mathrm{h} v-\mathrm{Eg})^{\mathrm{n} / 2}\left(\mathrm{n}=1\right.$ for $\left.\mathrm{Ag}_{3} \mathrm{PO}_{4}\right)$. Furthermore, the band-edge potentials for the conduction band $(\mathrm{CB})$ and valence band $(\mathrm{VB})$ can be calculated as $\mathrm{E}_{\mathrm{VB}}=\chi-\mathrm{E}_{\mathrm{H}}+0.5 \mathrm{Eg}$ and $\mathrm{E}_{\mathrm{CB}}=\mathrm{E}_{\mathrm{VB}}$ - Eg, respectively; here, $\chi$ is the electronegativity of the constituent atom (5.96 eV for $\left.\mathrm{Ag}_{3} \mathrm{PO}_{4}\right)$ and $\mathrm{E}_{\mathrm{H}}$ is the energy of the free electrons relative to the standard hydrogen reduction potential (approximately $4.5 \mathrm{eV}$ ). Thus, $\mathrm{E}_{\mathrm{VB}}$ and $\mathrm{E}_{\mathrm{CB}}$ of $\mathrm{Ag}_{3} \mathrm{PO}_{4}$ can be estimated to be 2.65 and $0.27 \mathrm{eV}$, respectively.

As another quality assurance method, the XPS analysis of the prepared $\mathrm{Ag}_{3} \mathrm{PO}_{4}, \mathrm{CuFeS}_{2}$, $\mathrm{CuFeS}_{2} / \mathrm{Ag}_{3} \mathrm{PO}_{4}$ composites (Figures 6-8, full scan) revealed that the prepared composites contained their own elements: $\mathrm{Ag}, \mathrm{P}, \mathrm{O}, \mathrm{Cu}, \mathrm{Fe}$, and S. High-resolution XPS revealed $\mathrm{Ag}_{3 \mathrm{~d}}, \mathrm{P}_{2 \mathrm{p}}, \mathrm{O}_{1 \mathrm{~s}}, \mathrm{Cu}_{2 \mathrm{p}}$, $\mathrm{Fe}_{2 p}$, and $\mathrm{S}_{2 \mathrm{p}}$ in $\mathrm{CuFeS}_{2} / \mathrm{Ag}_{3} \mathrm{PO}_{4}$ composites (Figure $8 \mathrm{~B}-\mathrm{G}$, respectively). In Figure 8B, the binding energies are located at 367.8 and $373.3 \mathrm{eV}$, corresponding to $\mathrm{Ag}^{+} 3 \mathrm{~d}_{5 / 2}$ and $\mathrm{Ag}^{+} 3 \mathrm{~d}_{3 / 2}$, respectively. Furthermore, the peak at $132.9 \mathrm{eV}$ correspond to $\mathrm{P}^{5+} 2 \mathrm{p}$ (Figure $8 \mathrm{C}$ ). $\mathrm{O} 1 \mathrm{~s}$ spectra can be deconvoluted into two component peaks of 531.8 and $530.7 \mathrm{eV}$ (Figure 8D). The peak centered at $530.7 \mathrm{eV}$ associated with the $\mathrm{O}_{2}$ in $\mathrm{Ag}_{3} \mathrm{PO}_{4}$. The other peak centered at $531.8 \mathrm{eV}$ the presence of $-\mathrm{OH}$ group or a water molecule absorbed on the surface of the prepared composites. In Figure $8 \mathrm{E}$, the peaks at 932.3, 934.2, 952.2 , and $953.8 \mathrm{eV}$ corresponded to $\mathrm{Cu}^{+} 2 \mathrm{p}_{3 / 2}, \mathrm{Cu}^{2+} 2 \mathrm{p}_{3 / 2}, \mathrm{Cu}^{+} 2 \mathrm{p}_{1 / 2}$, and $\mathrm{Cu}^{2+} 2 \mathrm{p}_{1 / 2}$, respectively. The peaks at 712.5, 718.2, 722.5, and $731.8 \mathrm{eV}$ corresponded to $\mathrm{Fe}^{2+} 2 \mathrm{p}_{3 / 2}, \mathrm{Fe}^{3+} 2 \mathrm{p}_{3 / 2}, \mathrm{Fe}^{2+} 2 \mathrm{p}_{1 / 2}$ and 
$\mathrm{Fe}^{3+} 2 \mathrm{p}_{1 / 2}$, respectively (Figure $8 \mathrm{~F}$ ), whereas that at 162.5 and $167.8 \mathrm{eV}$ corresponded to $\mathrm{S}^{2-} 2 \mathrm{p}$ and $\mathrm{S}^{6+}$ $2 p$, respectively (Figure $8 G$ ).
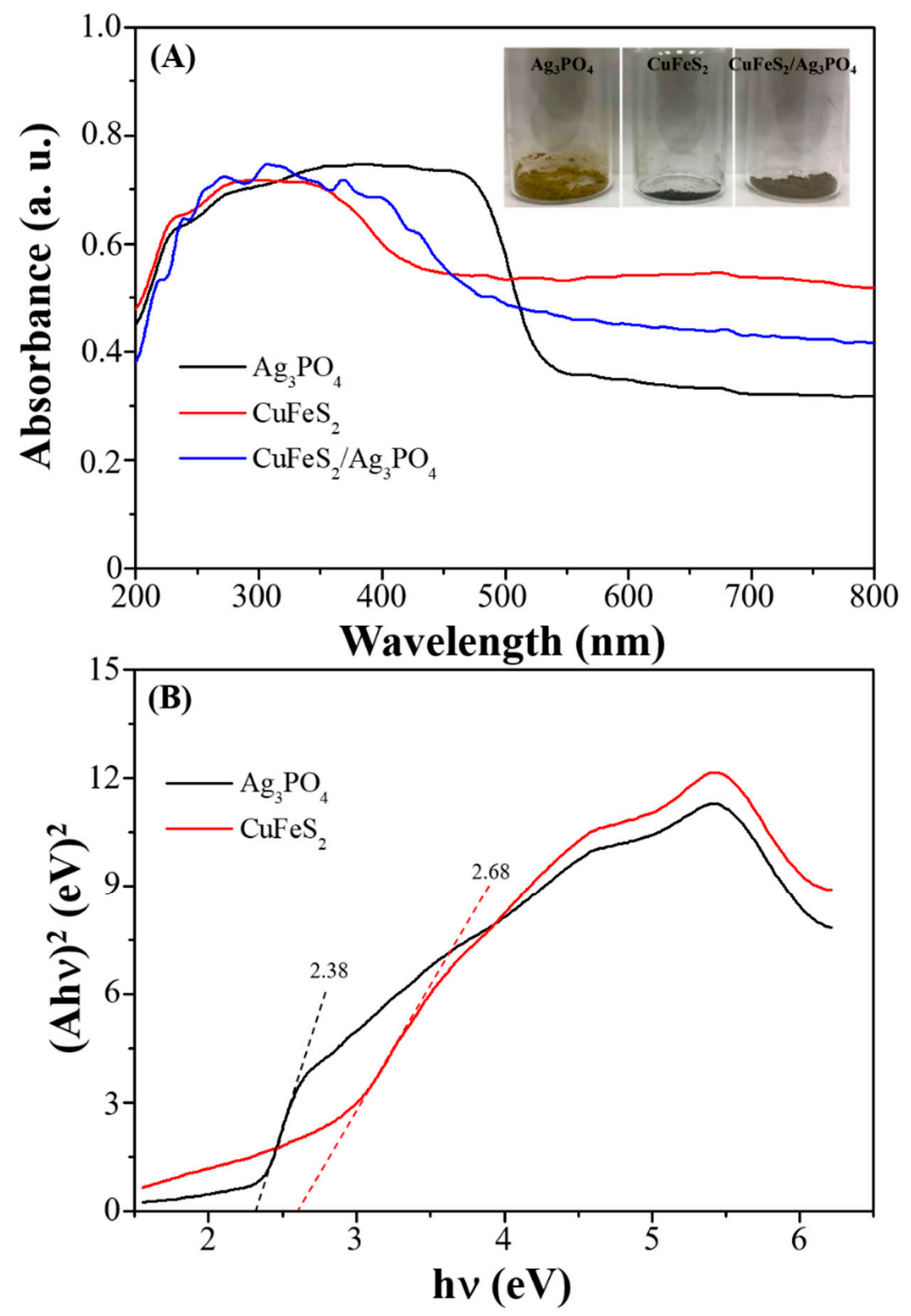

Figure 5. (A) UV-Vis diffuse reflectance spectroscopy (DRS) spectra and (B) Tauc's plots of different samples: $\mathrm{Ag}_{3} \mathrm{PO}_{4}$ (black), $\mathrm{CuFeS}_{2}$ (red), and $\mathrm{CuFeS}_{2} / \mathrm{Ag}_{3} \mathrm{PO}_{4}$ composites (blue). 

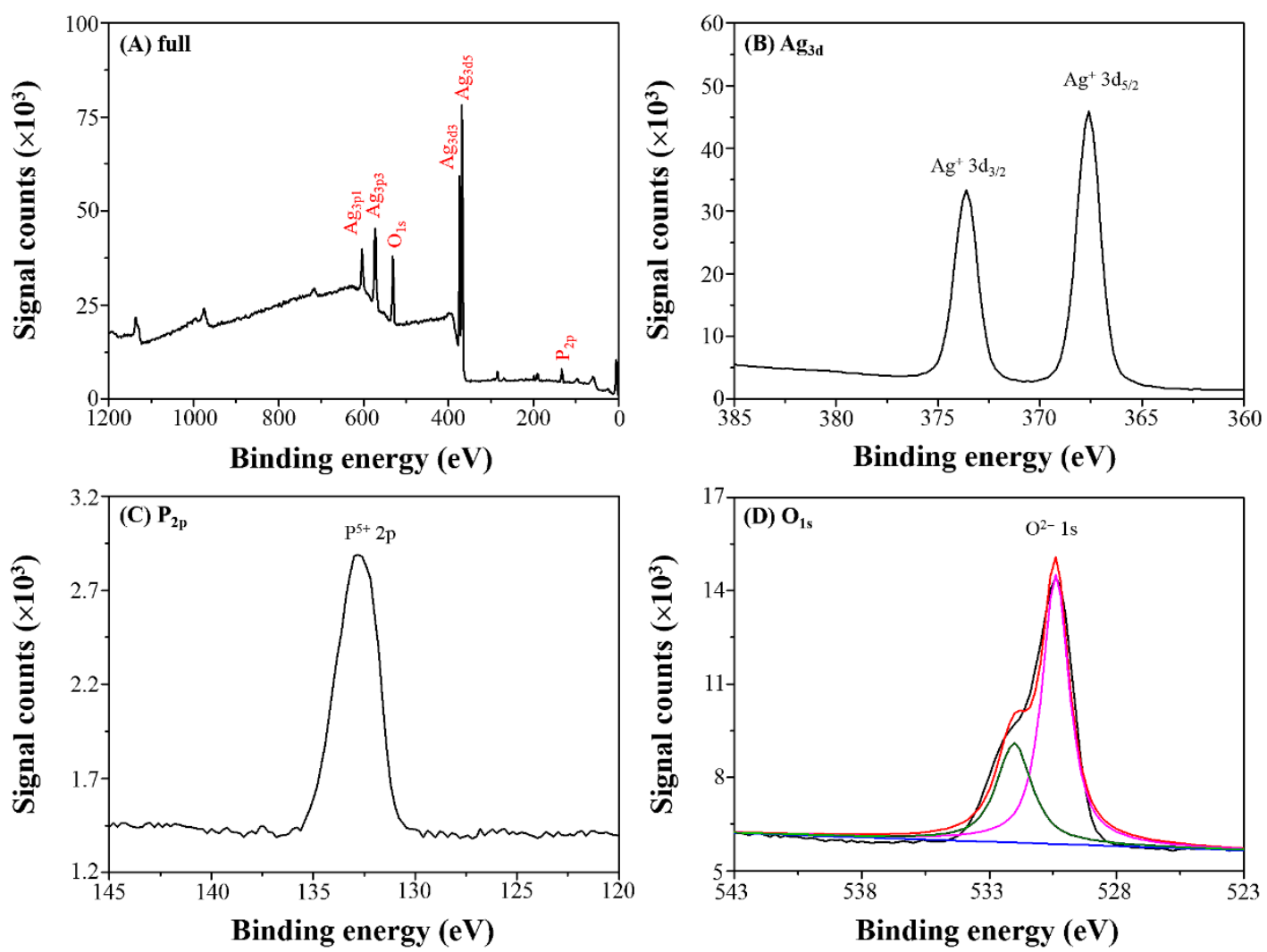

Figure 6. XPS spectra of $\mathrm{Ag}_{3} \mathrm{PO}_{4}$ : (A) full scan; (B) $\mathrm{Ag}_{3 \mathrm{~d}} ;$ (C) $\mathrm{P}_{2 \mathrm{p}}$; and (D) $\mathrm{O}_{1 \mathrm{~s}}$. Deconvolution of XPS peak for $\mathrm{O}_{1 \mathrm{~s}}$ element represented in different color line.
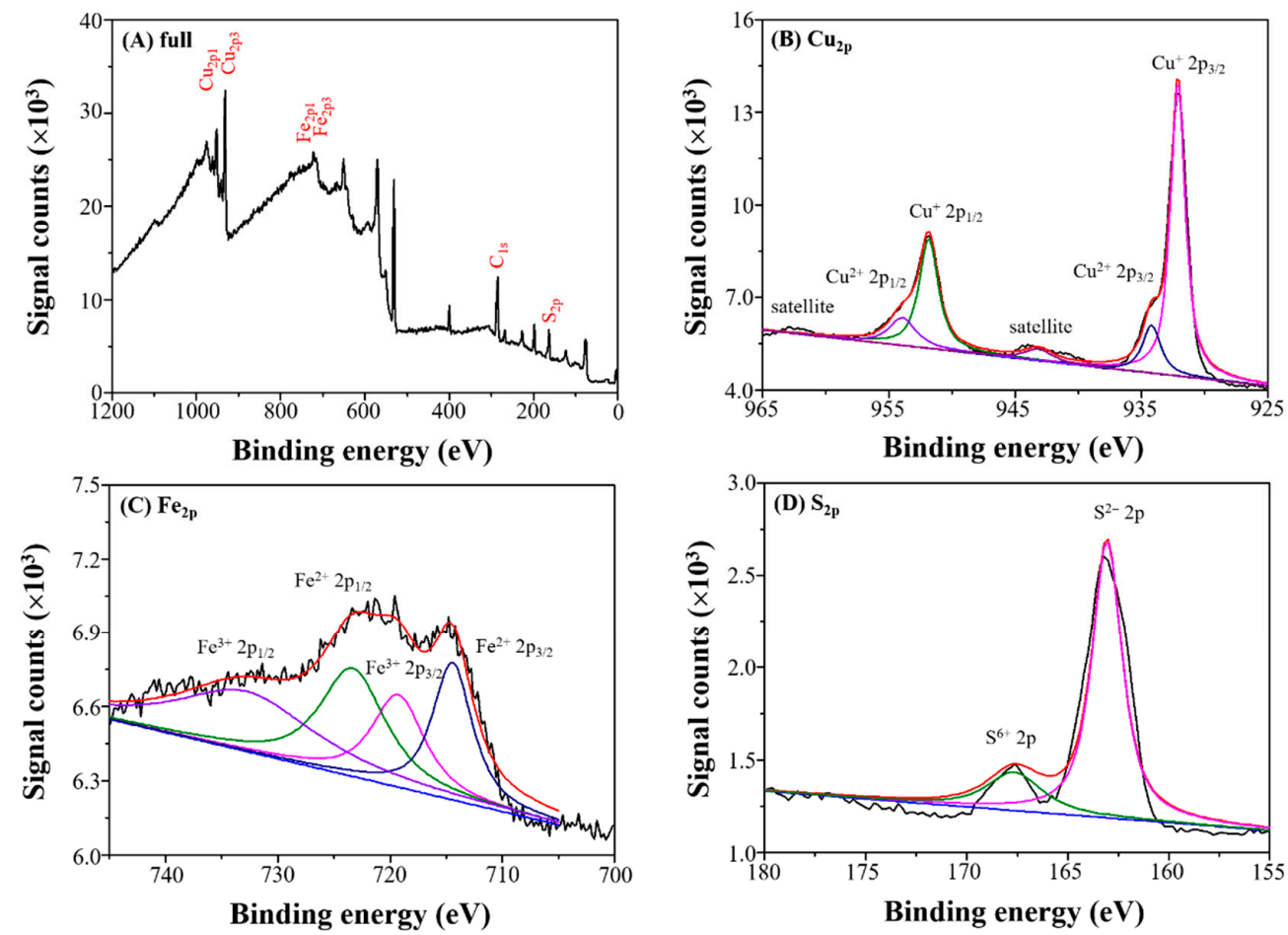

Figure 7. XPS spectra of $\mathrm{CuFeS}_{2}$ : (A) full scan; (B) $\mathrm{Cu}_{2 p}$; (C) $\mathrm{Fe}_{2 p}$; and (D) $\mathrm{S}_{2 p}$. Deconvolution of XPS peaks for $\mathrm{Cu}_{2 p}, \mathrm{Fe}_{2 p}$ and $\mathrm{S}_{2 p}$ elements represented in different color line. 

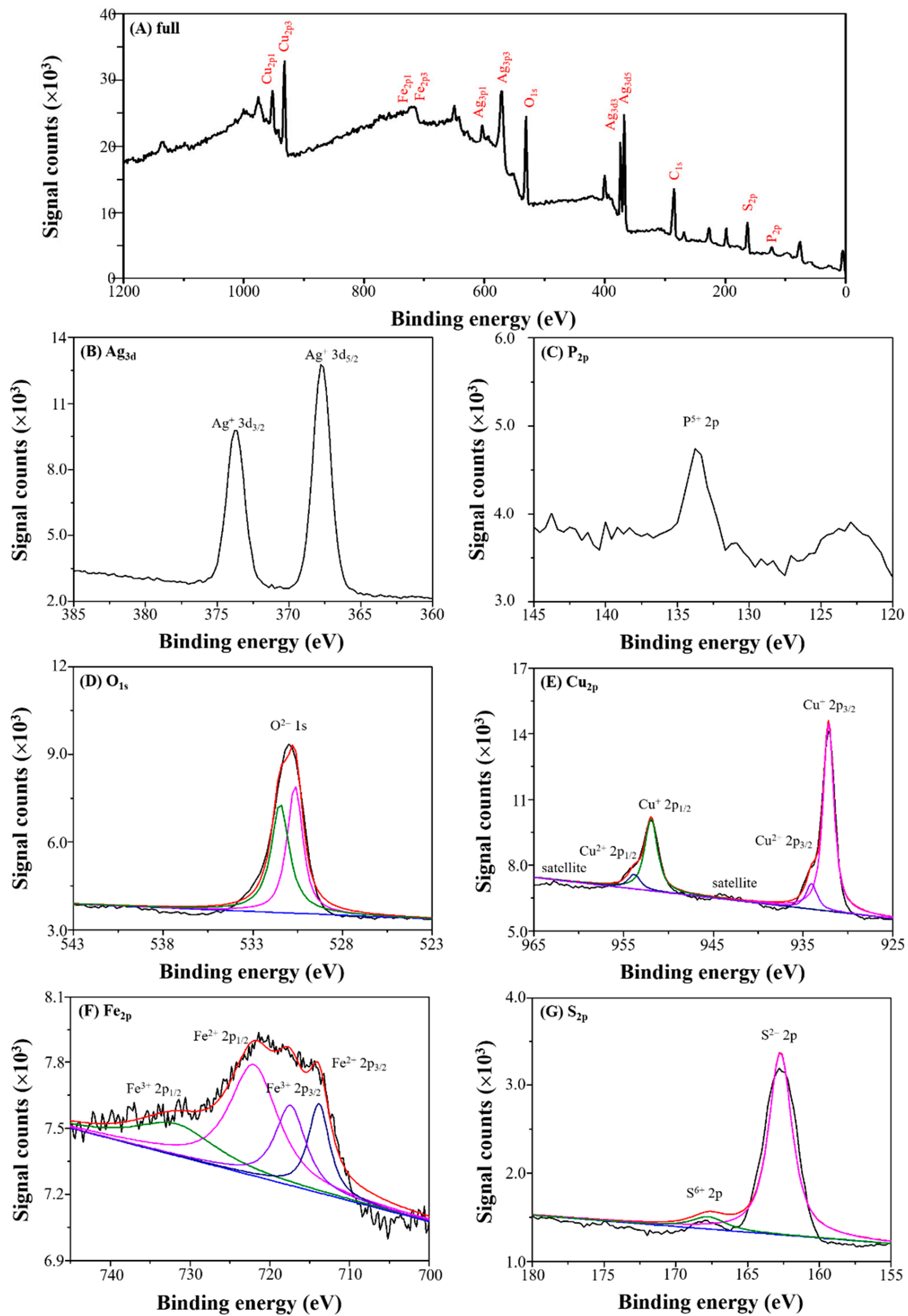

Figure 8. XPS spectra of $\mathrm{CuFeS}_{2} / \mathrm{Ag}_{3} \mathrm{PO}_{4}$ : (A) full scan; (B) $\mathrm{Ag}_{3 \mathrm{~d}} ;$ (C) $\mathrm{P}_{2 p} ;$ (D) $\mathrm{O}_{1 \mathrm{~s}} ;(\mathbf{E}) \mathrm{Cu}_{2 p}$; (F) $\mathrm{Fe}_{2 p}$; and (G) $\mathrm{S}_{2 p}$. Deconvolution of XPS peaks for $\mathrm{O}_{1 \mathrm{~s}}, \mathrm{Cu}_{2 p}, \mathrm{Fe}_{2 p}$ and $\mathrm{S}_{2 p}$ elements represented in different color line. 


\subsection{Degradation Performance of $\mathrm{Ag}_{3} \mathrm{PO}_{4}, \mathrm{CuFeS}$, and $\mathrm{CuFeS} \mathrm{S}_{2} / \mathrm{Ag}_{3} \mathrm{PO}_{4}$}

To evaluate the degradation activity of the prepared $\mathrm{Ag}_{3} \mathrm{PO}_{4}, \mathrm{CuFeS}$, and $\mathrm{CuFeS}_{2} / \mathrm{Ag}_{3} \mathrm{PO}_{4}$ composites, $\mathrm{RhB}$ was selected as the target pollutant. Figure 9 shows the concentration ratio $\left(\mathrm{C} / \mathrm{C}_{0}\right.$, where $\mathrm{C}_{0}$ and $\mathrm{C}$ represented the $\mathrm{RhB}$ concentration at the initial condition and at time $t$, respectively) of $\mathrm{RhB}$ by using $\mathrm{Ag}_{3} \mathrm{PO}_{4}, \mathrm{CuFeS}_{2}$, and $\mathrm{CuFeS}_{2} / \mathrm{Ag}_{3} \mathrm{PO}_{4}$ composites under three different degradation conditions: photocatalytic, Fenton, and photo-Fenton. First, under $30 \mathrm{~min}$ LED light irradiation (Figure 9A), the degradation efficiencies of $\mathrm{RhB}$ in $\mathrm{CuFeS}_{2}$ and $\mathrm{CuFeS}_{2} / \mathrm{Ag}_{3} \mathrm{PO}_{4}$ are only $8.9 \%$ and $16.9 \%$, respectively, whereas the efficiency reaches $39.5 \%$ in the presence of $\mathrm{Ag}_{3} \mathrm{PO}_{4}$. This suggests that the photocatalytic performance of $\mathrm{Ag}_{3} \mathrm{PO}_{4}$ is better than that of $\mathrm{CuFeS}_{2}$ and $\mathrm{CuFeS}_{2} / \mathrm{Ag}_{3} \mathrm{PO}_{4}$, attributable to the reactive radical formation from the effective photoinduced charge separation for $\mathrm{RhB}$ degradation. Nevertheless, these reactive radicals must be determined in a later experiment. $\mathrm{CuFeS} / \mathrm{Ag}_{3} \mathrm{PO}_{4}$ is responsive to visible light caused by its diluted amount of $\mathrm{Ag}_{3} \mathrm{PO}_{4}$, resulting in a weaker degradation performance than that of pure $\mathrm{Ag}_{3} \mathrm{PO}_{4}$. Second, the degradation efficiency of the prepared $\mathrm{Ag}_{3} \mathrm{PO}_{4}, \mathrm{CuFeS}_{2}$, and $\mathrm{CuFeS}_{2} / \mathrm{Ag}_{3} \mathrm{PO}_{4}$ composites through the Fenton reaction in the dark was studied (Figure $9 \mathrm{~B}$ ). The RhB concentration barely changes in the presence of $\mathrm{Ag}_{3} \mathrm{PO}_{4}$, but the $\mathrm{RhB}$ degradation efficiency reaches $76.1 \%$ and $93.7 \%$ within $1 \mathrm{~min}$ in the presence of $\mathrm{CuFeS}_{2}$ and $\mathrm{CuFeS} / \mathrm{Ag}_{3} \mathrm{PO}_{4}$, respectively. This is due to the production of hydroxyl radicals that degrade $\mathrm{RhB}$ from the oxidation of the $\mathrm{Cu}^{+} / \mathrm{Fe}^{2+}$ ions on the $\mathrm{CuFeS}_{2}$ to the formation of $\mathrm{Cu}^{2+} / \mathrm{Fe}^{3+}$ ions in the presence of $\mathrm{H}_{2} \mathrm{O}_{2}$. Finally, the degradation performance of the prepared $\mathrm{Ag}_{3} \mathrm{PO}_{4}, \mathrm{CuFeS}_{2}$, and $\mathrm{CuFeS} / \mathrm{Ag}_{3} \mathrm{PO}_{4}$ composites was evaluated with the photo-Fenton reaction in the presence of $\mathrm{H}_{2} \mathrm{O}_{2}$, and the results are shown in Figure $9 \mathrm{C}$. The degradation efficiency of $\mathrm{Ag}_{3} \mathrm{PO}_{4}$ reaches $25 \%$ with a $10 \mathrm{~min}$ photo-Fenton reaction, whereas that of $\mathrm{CuFeS}_{2}$ reaches $87.7 \%$ within 1 min. Notably, the degradation efficiency of $\mathrm{CuFeS}_{2} / \mathrm{Ag}_{3} \mathrm{PO}_{4}$ reaches $96 \%$ within $1 \mathrm{~min}$. Moreover, the relative standard deviation of the degradation performance for three different batches of the prepared composites was less than $9 \%$, indicating the high reproducibility of the preparation methods for the proposed composites. In addition, we also analyzed the degradation performances of $\mathrm{Cu}_{2} \mathrm{~S}, \mathrm{Fe}_{2} \mathrm{~S}_{3}, \mathrm{Cu}_{2} \mathrm{~S} / \mathrm{Ag}_{3} \mathrm{PO}_{4}$ and $\mathrm{Fe}_{2} \mathrm{~S}_{3} / \mathrm{Ag}_{3} \mathrm{PO}_{4}$ composites. As shown in Figure 10, the RhB degradation efficiency reaches $75.2 \%, 86.5 \%, 81.4 \%$ and $90.4 \%$ within $1 \mathrm{~min}$ in the presence of $\mathrm{Cu}_{2} \mathrm{~S}, \mathrm{Fe}_{2} \mathrm{~S}_{3}, \mathrm{Cu}_{2} \mathrm{~S} / \mathrm{Ag}_{3} \mathrm{PO}_{4}$ and $\mathrm{Fe}_{2} \mathrm{~S}_{3} / \mathrm{Ag}_{3} \mathrm{PO}_{4}$, respectively. These results suggested that the addition of $\mathrm{CuFeS}_{2} / \mathrm{Ag}_{3} \mathrm{PO}_{4}$ promotes the production of hydroxyl radicals through the photo-Fenton reaction to degrade $\mathrm{RhB}$ at a higher efficiency than $\mathrm{CuFeS}_{2}, \mathrm{Cu}_{2} \mathrm{~S}$, $\mathrm{Fe}_{2} \mathrm{~S}_{3}$ alone, indicating a synergistic effect between $\mathrm{CuFeS}_{2}$ and $\mathrm{Ag}_{3} \mathrm{PO}_{4}$. Figure 9D-F showed the corresponded pseudo-first order linear transform of $\mathrm{RhB}$ degradation under photocatalytic reaction, Fenton reaction and photo-Fenton reaction by $\mathrm{Ag}_{3} \mathrm{PO}_{4}, \mathrm{CuFeS}_{2}$, and $\mathrm{CuFeS}_{2} / \mathrm{Ag}_{3} \mathrm{PO}_{4}$ composites. The apparent rate constants for $\mathrm{RhB}$ degradation by $\mathrm{Ag}_{3} \mathrm{PO}_{4}, \mathrm{CuFeS}$, and $\mathrm{CuFeS}_{2} / \mathrm{Ag}_{3} \mathrm{PO}_{4}$ composites are listed in Table 1.

Table 1. Pseudo-first-order rate constants for rhodamine B (RhB) degradation by $\mathrm{Ag}_{3} \mathrm{PO}_{4}, \mathrm{CuFeS}_{2}$, and $\mathrm{CuFeS} / \mathrm{Ag}_{3} \mathrm{PO}_{4}$ composites at different conditions.

\begin{tabular}{clccc}
\hline \multirow{2}{*}{ Series } & Degradation Mode & $\begin{array}{c}\text { Pseudo-First-Order } \\
\text { Kinetic Equation }\end{array}$ & $\mathbf{k}\left(\mathbf{m i n}^{\mathbf{- 1})}\right.$ & $\mathbf{R}^{\mathbf{2}}$ \\
\hline \multirow{2}{*}{$\mathrm{Ag}_{3} \mathrm{PO}_{4}$} & Photocatalytic reaction & $\mathrm{y}=0.016 \mathrm{x}+0.048$ & 0.016 & 0.96 \\
& Fenton reaction & $\mathrm{y}=0.0026 \mathrm{x}+0.0088$ & 0.0026 & 0.92 \\
& Photo-Fenton reaction & $\mathrm{y}=0.0047 \mathrm{x}+0.055$ & 0.0047 & 0.80 \\
\hline \multirow{2}{*}{$\mathrm{CuFeS}$} & Photocatalytic reaction & $\mathrm{y}=0.0007 \mathrm{x}-0.039$ & 0.0007 & 0.72 \\
& Fenton reaction & $\mathrm{y}=1.5 \mathrm{x}-0.16$ & 1.5 & 0.93 \\
& Photo-Fenton reaction & $\mathrm{y}=2.8 \mathrm{x}-0.29$ & 2.8 & 0.94 \\
\hline \multirow{2}{*}{$\mathrm{CuFeS}_{2} / \mathrm{Ag}_{3} \mathrm{PO}_{4}$} & Photocatalytic reaction & $\mathrm{y}=0.018 \mathrm{x}-0.0015$ & 0.018 & 0.94 \\
& Fenton reaction & $\mathrm{y}=2.2 \mathrm{x}-0.156$ & 2.2 & 0.99 \\
& Photo-Fenton reaction & $\mathrm{y}=3.3 \mathrm{x}-0.0322$ & 3.3 & 0.97 \\
\hline
\end{tabular}



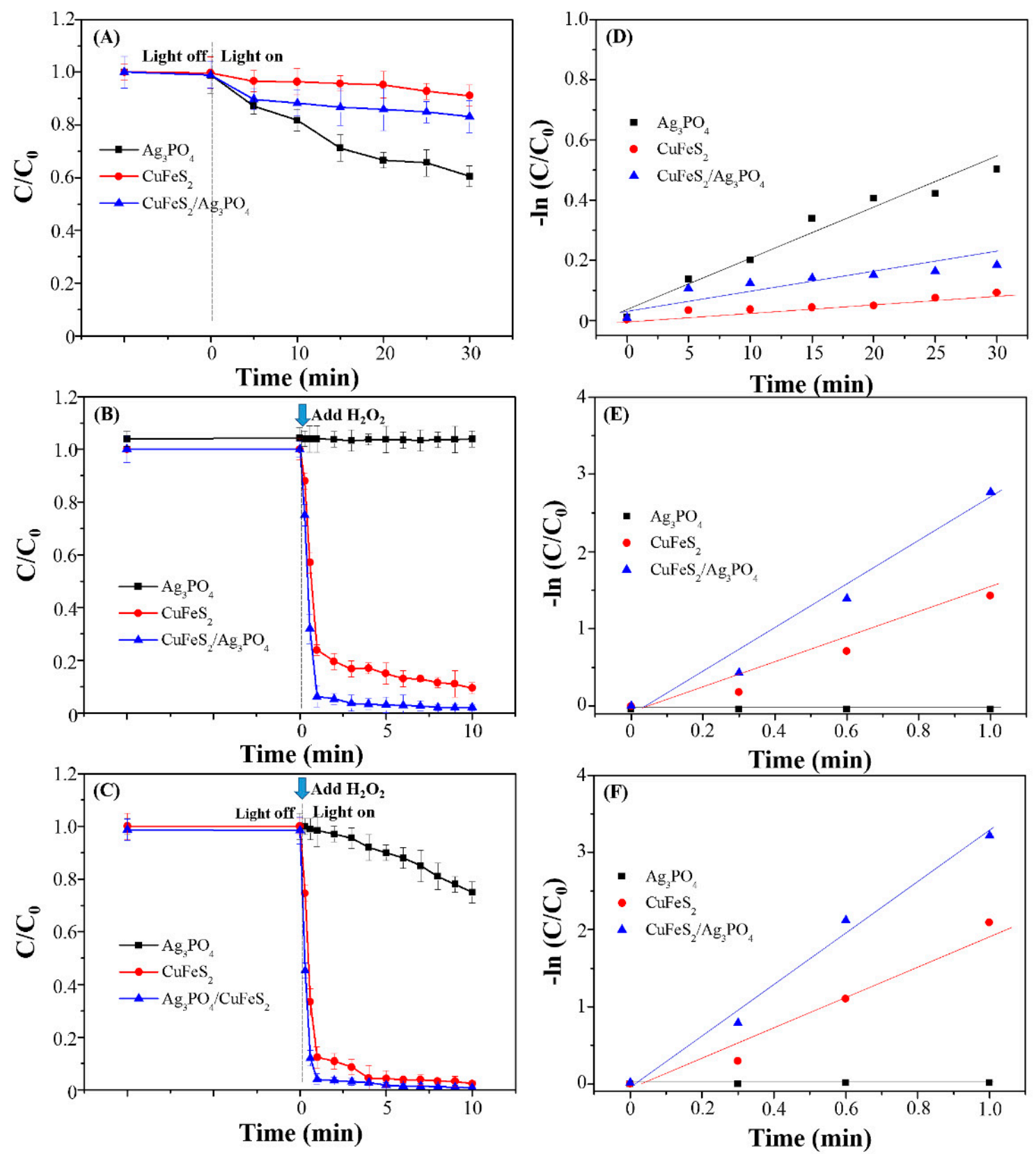

Figure 9. (A) Photocatalytic reaction; (B) fenton reaction; and (C) photo-Fenton reaction for RhB degradation by different samples: $\mathrm{Ag}_{3} \mathrm{PO}_{4}$ (black), $\mathrm{CuFeS}_{2}$ (red), and $\mathrm{CuFeS}_{2} / \mathrm{Ag}_{3} \mathrm{PO}_{4}$ composites (blue). The pseudo-first order linear transform of RhB degradation under (D) photocatalytic reaction, (E), Fenton reaction and (F) photo-Fenton reaction by different samples: $\mathrm{Ag}_{3} \mathrm{PO}_{4}$ (black), $\mathrm{CuFeS}_{2}$ (red), and $\mathrm{CuFeS}_{2} / \mathrm{Ag}_{3} \mathrm{PO}_{4}$ composites (blue).

To maximize the degradation performance of $\mathrm{CuFeS}_{2} / \mathrm{Ag}_{3} \mathrm{PO}_{4}$, the following factors were systematically studied: the molar ratio of $\mathrm{CuFeS}_{2}$ to $\mathrm{Ag}_{3} \mathrm{PO}_{4}$, the mechanical mixing of $\mathrm{CuFeS}_{2}$ and $\mathrm{Ag}_{3} \mathrm{PO}_{4}$ particles, and the added amounts of $\mathrm{H}_{2} \mathrm{O}_{2}$ and $\mathrm{CuFeS} / \mathrm{Ag}_{3} \mathrm{PO}_{4}$. Figure $11 \mathrm{~A}$ presents the plots of the $\mathrm{RhB}$ concentration ratio $\left(\mathrm{C} / \mathrm{C}_{0}\right)$ against the reaction time for $\mathrm{CuFeS}_{2} / \mathrm{Ag}_{3} \mathrm{PO}_{4}$ prepared at different precursor molar ratios from $\mathrm{CuFeS}_{2}$ to $\mathrm{Ag}_{3} \mathrm{PO}_{4}$. The degradation efficiency can be visually related to the highest drop in the $\mathrm{RhB}$ concentration ratio in the plots during the reaction. The higher molar ratio of the precursors used to make $\mathrm{CuFeS}_{2} / \mathrm{Ag}_{3} \mathrm{PO}_{4}$ resulted in higher degradation efficiency as the hydroxyl radicals generated from the photo-Fenton reaction dominated the RhB degradation. 
Above the 2.5:1 ratio, the suspension of excessive black $\mathrm{CuFeS}$, particles in the $\mathrm{CuFeS}_{2} / \mathrm{Ag}_{3} \mathrm{PO}_{4}$ solution was observed. This raised a concern as the excessive $\mathrm{CuFeS}_{2}$ particles were not coupled with $\mathrm{Ag}_{3} \mathrm{PO}_{4}$ during the synthesis, and they cannot be regenerated during the photolysis. $\mathrm{CuFeS}_{2} / \mathrm{Ag}_{3} \mathrm{PO}_{4}$ with the molar ratio of 2.5:1 was therefore selected as the optimal condition for this study. The second experiment was performed by mechanically mixing both $\mathrm{CuFeS}_{2}$ and $\mathrm{Ag}_{3} \mathrm{PO}_{4}$ particles with the molar ratio of 2.5:1 to prove the synergistic effect within $\mathrm{CuFeS}_{2} / \mathrm{Ag}_{3} \mathrm{PO}_{4}$ in the enhanced degradation activity (Figure 11B). The degradation efficiency for the mechanically mixed sample with 10 min photocatalytic, Fenton, and photo-Fenton reactions is $4.2 \%, 83.5 \%$, and $87.7 \%$, respectively-all evidently lower than that for composites formed with cyclic microwave heating (Figure 9). These results strongly suggest that the coupling interaction between $\mathrm{CuFeS}_{2}$ and $\mathrm{Ag}_{3} \mathrm{PO}_{4}$ is critical for the significantly enhanced degradation activity of $\mathrm{CuFeS}_{2} / \mathrm{Ag}_{3} \mathrm{PO}_{4}$ composites. Then, because the amount of $\mathrm{H}_{2} \mathrm{O}_{2}$ is key for the photo-Fenton reaction, its content in the degradation process may influence the performance of $\mathrm{CuFeS}_{2} / \mathrm{Ag}_{3} \mathrm{PO}_{4}$ composites. As shown in Figure 11C, the degradation efficiency increased with an increase in the $\mathrm{H}_{2} \mathrm{O}_{2}$ amount up to $200 \mu \mathrm{L}$, above which the degradation efficiency decreased, probably because excess reactive radicals react with one another. Thus, we selected $200 \mu \mathrm{L}$ of $\mathrm{H}_{2} \mathrm{O}_{2}$ as the optimum required amount of $\mathrm{H}_{2} \mathrm{O}_{2}$. Then, the degradation efficiency at different amounts of $\mathrm{CuFeS}_{2} / \mathrm{Ag}_{3} \mathrm{PO}_{4}$ composites was evaluated. As shown in Figure 11D, the degradation efficiency increased with an increase in the $\mathrm{CuFeS}_{2} / \mathrm{Ag}_{3} \mathrm{PO}_{4}$ amount of up to $20 \mathrm{mg}$, above which the degradation efficiency plateaued. On the basis of this result, $20 \mathrm{mg}$ of $\mathrm{CuFeS}_{2} / \mathrm{Ag}_{3} \mathrm{PO}_{4}$ was used for further investigations. Finally, the degradation efficiency for a higher $\mathrm{RhB}$ concentration at $20 \mathrm{mg} \mathrm{CuFeS} / \mathrm{Ag}_{3} \mathrm{PO}_{4}$ was evaluated. As shown in Figure 11E, the degradation efficiency at a higher RhB concentration decreased within $10 \mathrm{~min}$ of photo-Fenton reaction. However, the degraded $\mathrm{RhB}$ amount was higher at a higher $\mathrm{RhB}$ concentration. The results also indicated that the maximum degraded amount of $\mathrm{RhB}$ at $20 \mathrm{mg} \mathrm{CuFeS} / \mathrm{Ag}_{3} \mathrm{PO}_{4}$ was $54.9 \mathrm{ppm}$.
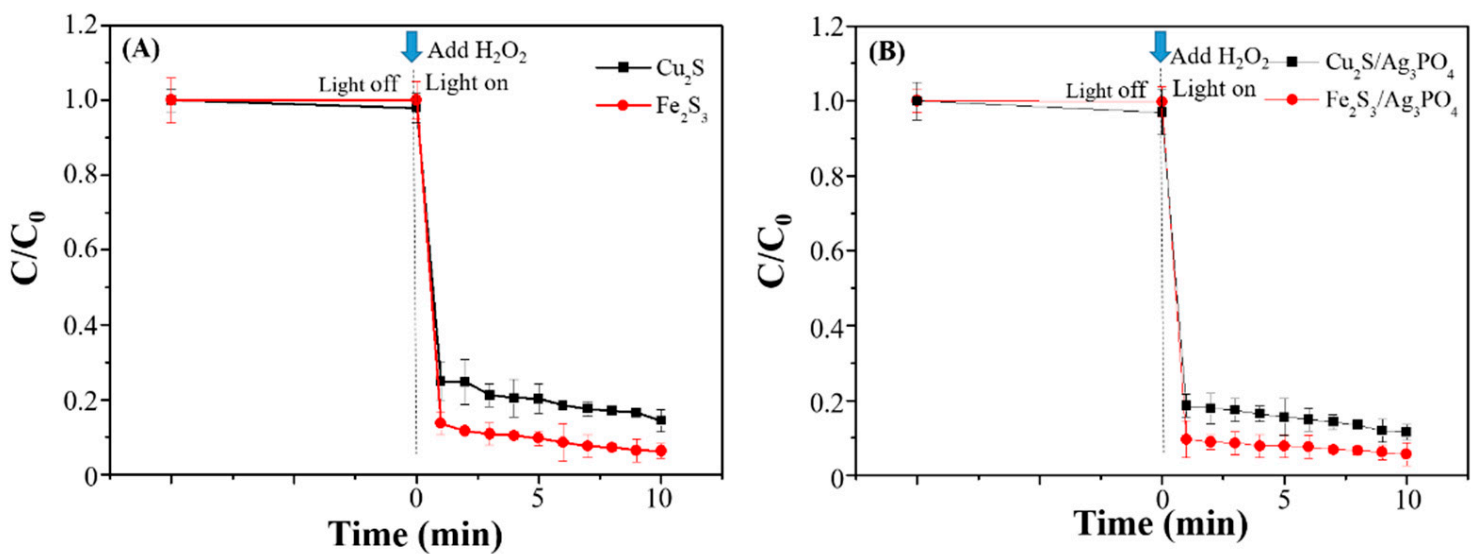

Figure 10. Photo-Fenton reaction for RhB degradation by different samples: (A) $\mathrm{Cu}_{2} \mathrm{~S}$ (black) and $\mathrm{Fe}_{2} \mathrm{~S}_{3}$ (red); and (B) $\mathrm{Cu}_{2} \mathrm{~S} / \mathrm{Ag}_{3} \mathrm{PO}_{4}$ (black) and $\mathrm{Fe}_{2} \mathrm{~S}_{3} / \mathrm{Ag}_{3} \mathrm{PO}_{4}$ (red) composites.

According to the literature, deethylation and chromophore cleavage are analogous competitive photodegradation reactions during the photocatalytic decomposition of organic pollutants. Based on the literature, the hypsochromic shifts (blue shift of the maximum absorption band) are attributed to the formation of a series of N-deethylated intermediates of RhB [31,32]. In this study, the absorption at $550 \mathrm{~nm}$ for $\mathrm{RhB}$ decreased with the increase in the reaction time and exhibited a slight hypochromic shift (dash line in Figure 12A). Therefore, a possible method to degrade RhB is through chromophore cleavage, which can be observed with an insignificant hypochromic shift in the UV-Vis spectra. Another approach to study organic compound degradation is to measure the TOC of the solution before and after the reaction. Figure 12B plots the temporal evolution of TOC content with RhB degradation by $\mathrm{CuFeS}_{2} / \mathrm{Ag}_{3} \mathrm{PO}_{4}$. Initially, the color vanished in the $\mathrm{RhB}$ solution with the photo-Fenton reaction for 
$1 \mathrm{~min}$; the TOC content decreased to $13.5 \mathrm{ppm}$ (decomposing only $2.17 \%$ of the original concentration (13.8 ppm)). The decomposition of $\mathrm{RhB}$ with $\mathrm{CuFeS}_{2} / \mathrm{Ag}_{3} \mathrm{PO}_{4}$ increased to as high as $78.3 \%$, but only $3.0 \mathrm{ppm}$ TOC remained in the solution with a $30 \mathrm{~min}$ photo-Fenton reaction. Evidence from both experimental approaches strongly supports $\mathrm{RhB}$ chromophore cleavage and $\mathrm{CO}_{2}$ production as the predominant pathways of degradation by $\mathrm{CuFeS} 2 / \mathrm{Ag}_{3} \mathrm{PO}_{4}$.

\subsection{Degradation Mechanism of $\mathrm{Ag}_{3} \mathrm{PO}_{4}, \mathrm{CuFeS} 2$, and $\mathrm{CuFeS} 2 / \mathrm{Ag}_{3} \mathrm{PO}_{4}$}

In photodegradation, the rate and the stability of electron-hole pairs generated from the excitation source are critical factors to be considered in the development of ideal photocatalysts. In this study, the separation efficiency and recombination rate of the electron-hole pairs for the prepared $\mathrm{Ag}_{3} \mathrm{PO}_{4}$, $\mathrm{CuFeS}_{2}$, and $\mathrm{CuFeS}_{2} / \mathrm{Ag}_{3} \mathrm{PO}_{4}$ composites were investigated through photocatalytic degradation without any $\mathrm{H}_{2} \mathrm{O}_{2}$. Figure $13 \mathrm{~A}$ shows the photocurrent density of $\mathrm{Ag}_{3} \mathrm{PO}_{4}, \mathrm{CuFeS}_{2}$, and $\mathrm{CuFeS}_{2} / \mathrm{Ag}_{3} \mathrm{PO}_{4}$ under LED light irradiation; all samples produced a sharp photocurrent peak on turning the light on and no peak as the light turned off, with photocurrent response during the on/off cycles. Under LED light irradiation, the current density decreased in the following order: $\mathrm{Ag}_{3} \mathrm{PO}_{4}>\mathrm{CuFeS}_{2} / \mathrm{Ag}_{3} \mathrm{PO}_{4}$ $>\mathrm{CuFeS}_{2}$. This result is consistent with the photocatalytic degradation results shown in Figure 9A, indicating that the differences in the photodegradation activity was due to the differences in the optoelectrical properties of selected materials. In addition, the different noise levels and shape forms of the photocurrent density for different composites may be attributed to the different size and morphology of the composites deposited on the fluorine-doped tin oxide (FTO) substrates. As a further experiment, the intensity of PL emission for three materials was measured to quantify the recombination rate of the electron-hole pairs; a lower rate implies a lower luminescence emission intensity and higher photocatalytic activity. Figure 13B presents the PL emission spectra of the prepared $\mathrm{Ag}_{3} \mathrm{PO}_{4}, \mathrm{CuFeS}_{2}$, and $\mathrm{CuFeS}_{2} / \mathrm{Ag}_{3} \mathrm{PO}_{4}$ composites at $\lambda_{\text {ex }}=250 \mathrm{~nm}$. The emission intensity of $\mathrm{CuFeS}_{2}$ was the weakest due to the lowest yield of electron-hole pairs but not due to a low recombination rate. The difference in the emission intensity between $\mathrm{Ag}_{3} \mathrm{PO}_{4}$ and $\mathrm{CuFeS}_{2} / \mathrm{Ag}_{3} \mathrm{PO}_{4}$ is nonsignificant, indicating comparable electron-hole pair recombination rates. This demonstrates the ability of $\mathrm{CuFeS}_{2} / \mathrm{Ag}_{3} \mathrm{PO}_{4}$ to generate electron-hole pairs with a low recombination rate, providing critical information to understand the mechanism discussed later. 

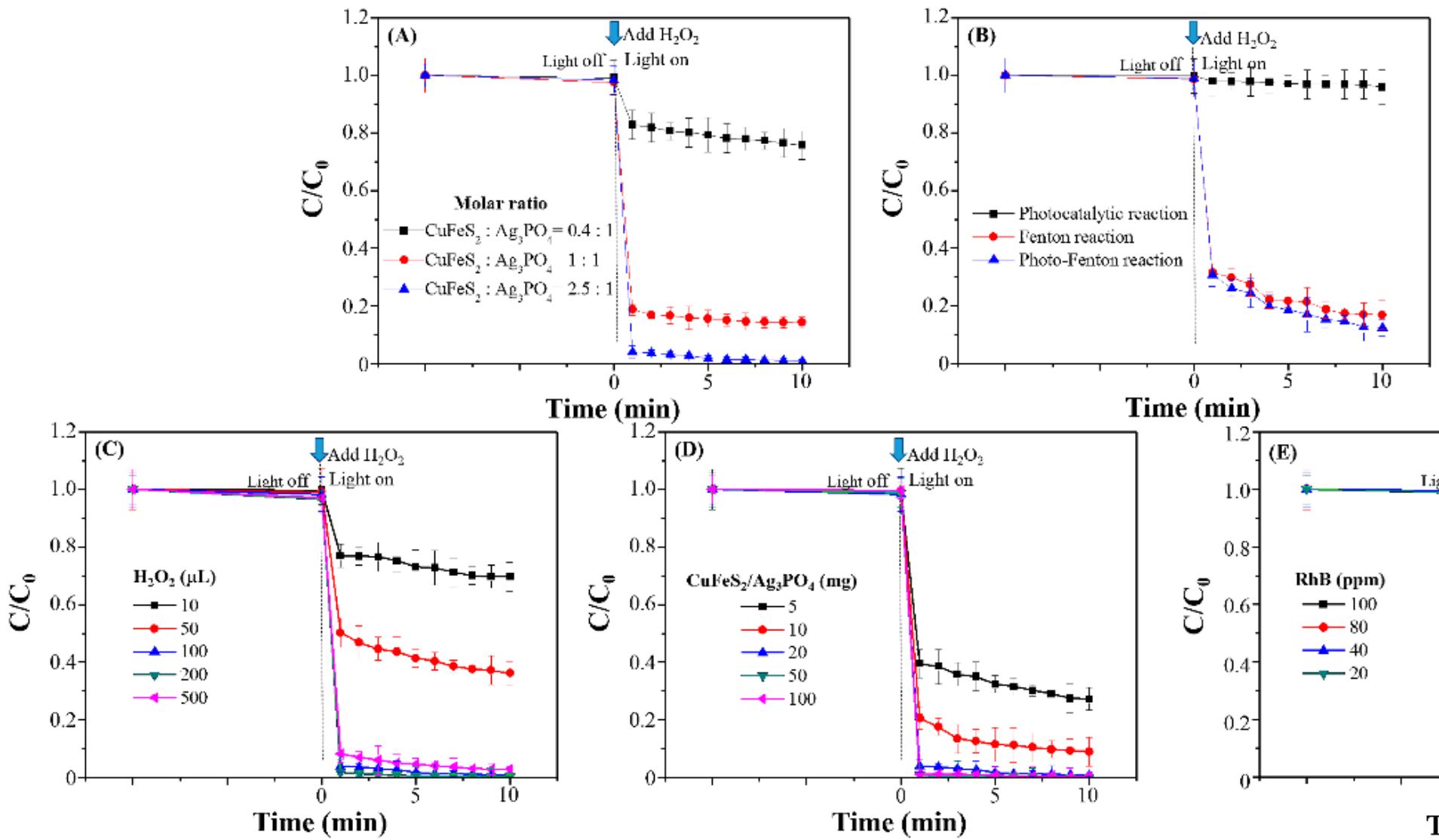

Time (min)

Time (min)
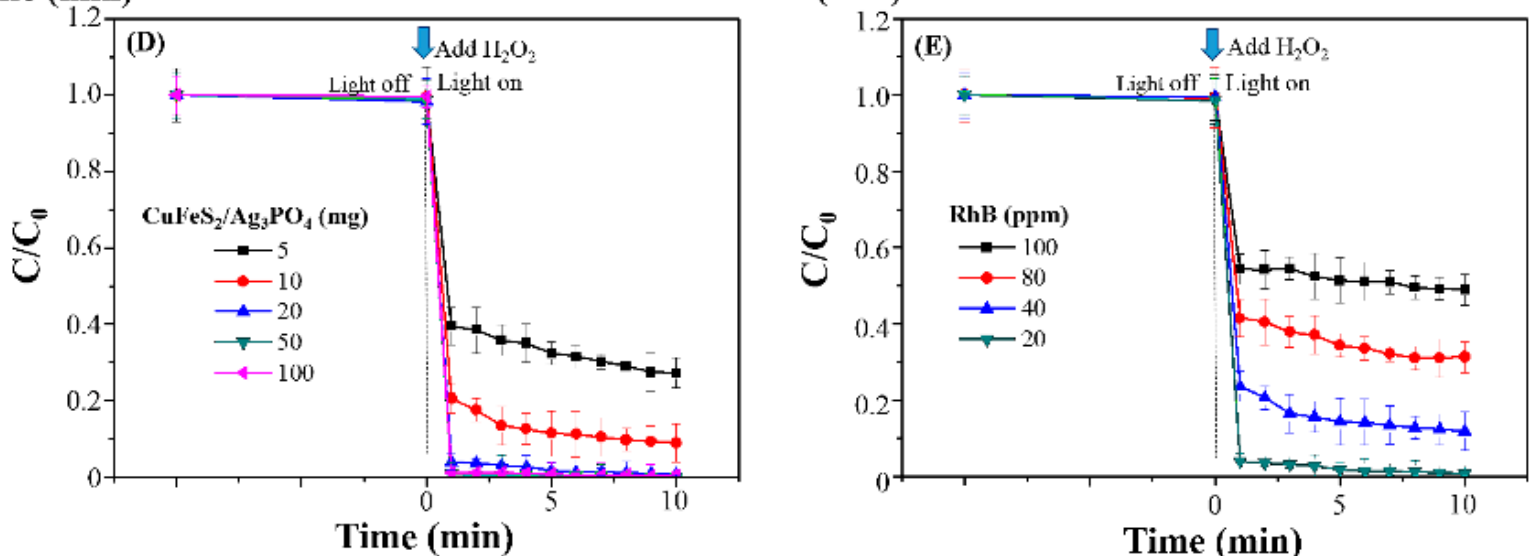

Figure 11. Degradation of $\mathrm{RhB}$ under different conditions: (A) different molar ratios of $\mathrm{CuFeS}_{2}$ to $\mathrm{Ag}_{3} \mathrm{PO}_{4} ;$ (B) different degradation procedures using the mechanical mixing of $\mathrm{Ag}_{3} \mathrm{PO}_{4}$ and $\mathrm{CuFeS}_{2}$ particles; (C) different amounts of $\mathrm{H}_{2} \mathrm{O}_{2}$ by $\mathrm{CuFeS}_{2} / \mathrm{Ag}_{3} \mathrm{PO}_{4}$ composites; (D) different amounts of CuFeS$/ \mathrm{Ag}_{3} \mathrm{PO}_{4}$ composites; and (E) different amounts of RhB. 


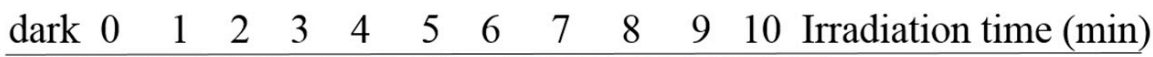
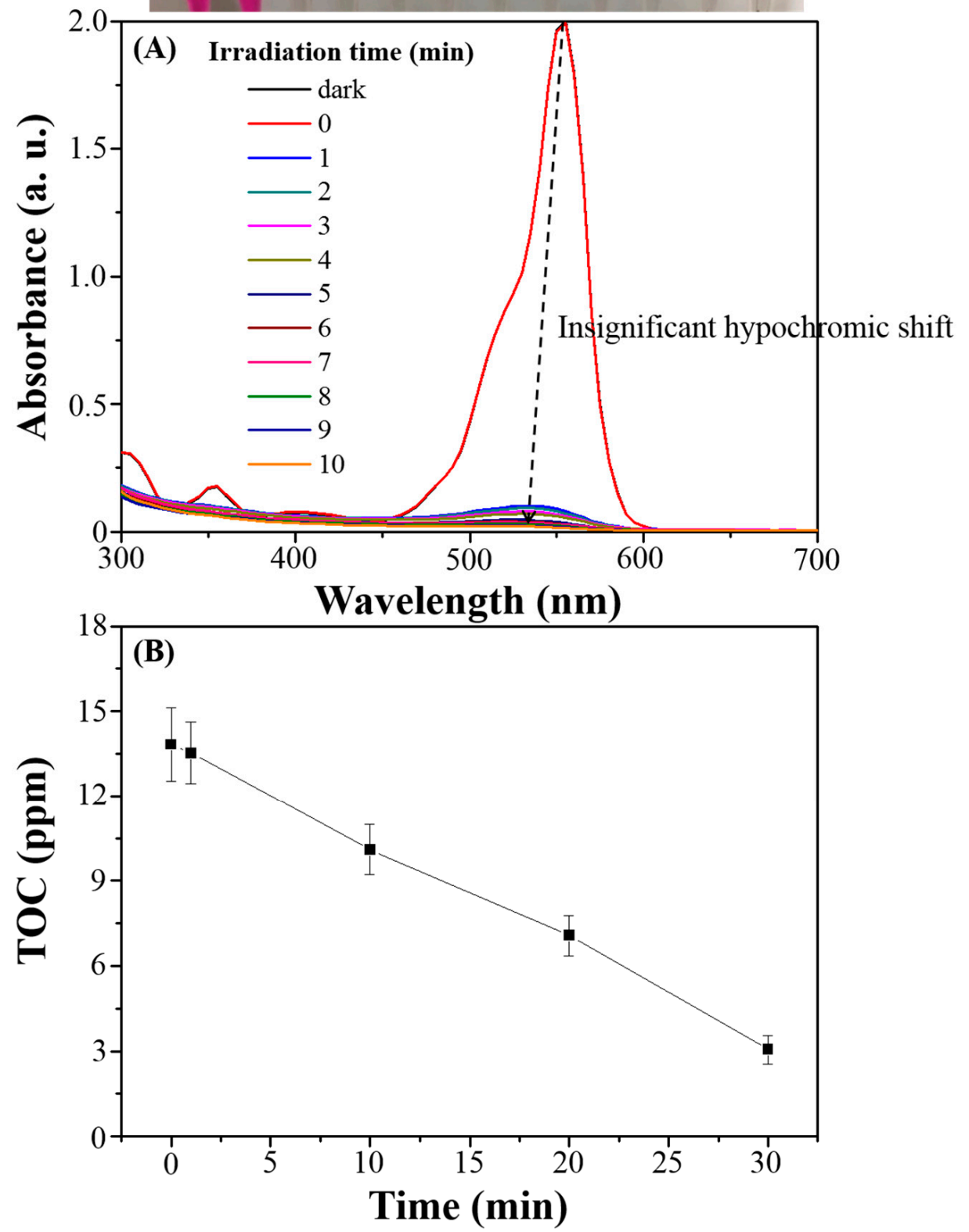

Figure 12. (A) Temporal evolution of UV-Vis spectra of RhB and (B) the corresponding total organic carbon (TOC) content of $\mathrm{RhB}$ degradation by the prepared $\mathrm{CuFeS}_{2} / \mathrm{Ag}_{3} \mathrm{PO}_{4}$ composites through the photo-Fenton reaction. Top image: photographs of the RhB solution under the photo-Fenton reaction at different irradiation time. 

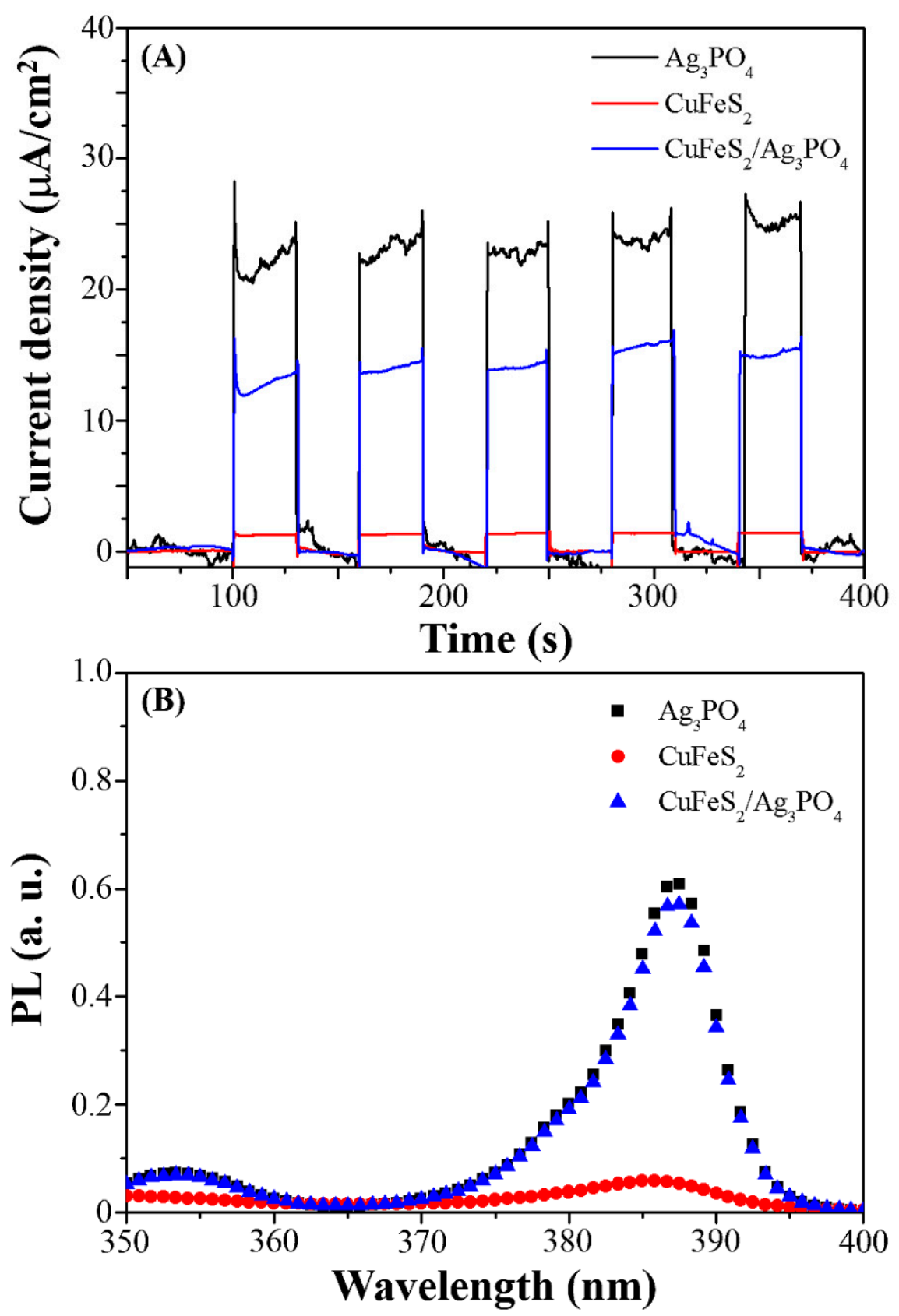

Figure 13. (A) Photocurrent density and (B) the photoluminescence (PL) spectra of different samples: $\mathrm{Ag}_{3} \mathrm{PO}_{4}$ (black), $\mathrm{CuFeS}$ (red), and $\mathrm{CuFeS}_{2} / \mathrm{Ag}_{3} \mathrm{PO}_{4}$ composites (blue).

As a key mechanistic study, the active species involved in the degradation reaction were identified systematically using the free radical trapping experiments (Figure 14). EDTA, BQ, and t-BuOH were used as holes, oxygen radicals, and hydroxyl radical scavengers, respectively. After adding EDTA to the reaction mixture, $\mathrm{RhB}$ degradation in $\mathrm{Ag}_{3} \mathrm{PO}_{4}$ samples was inhibited, indicating that holes are the major species involved in the photo-Fenton degradation (Figure 14A). In contrast to the $\mathrm{Ag}_{3} \mathrm{PO}_{4}$ sample, $\mathrm{RhB}$ degradation in $\mathrm{CuFeS}_{2}$ and $\mathrm{CuFeS} / \mathrm{Ag}_{3} \mathrm{PO}_{4}$ composites with the photo-Fenton reaction was inhibited by adding t-BuOH, indicating that hydroxyl radicals are the major active species (Figure 14B,C). 


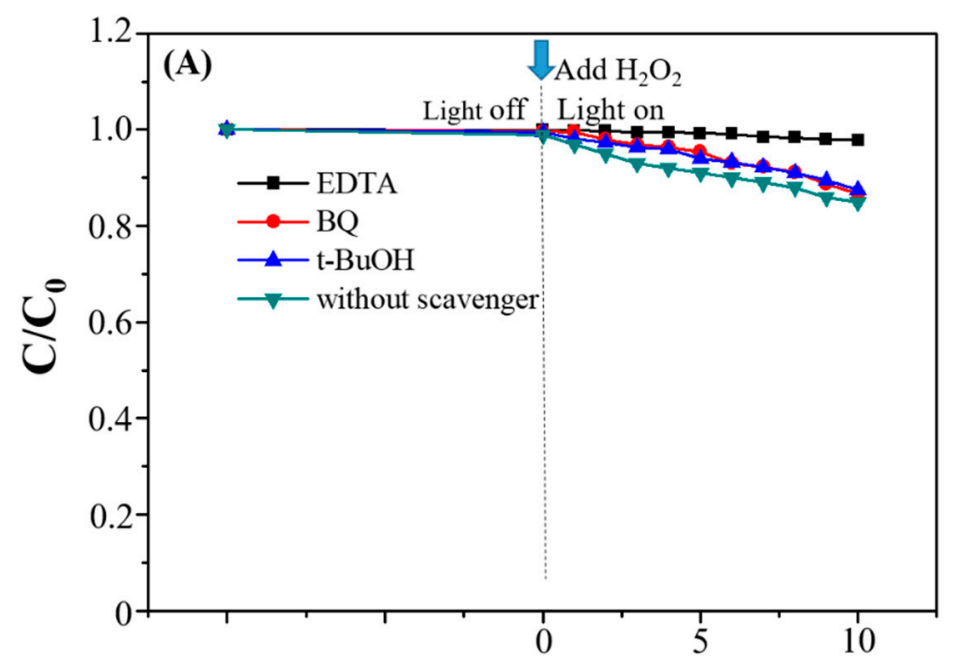

Time (min)

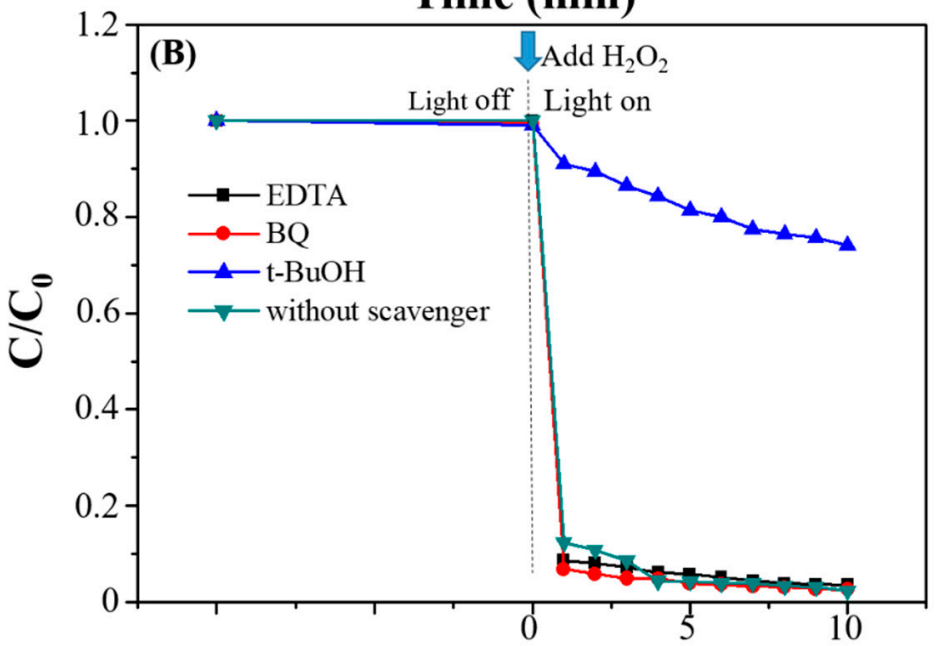

Time (min)

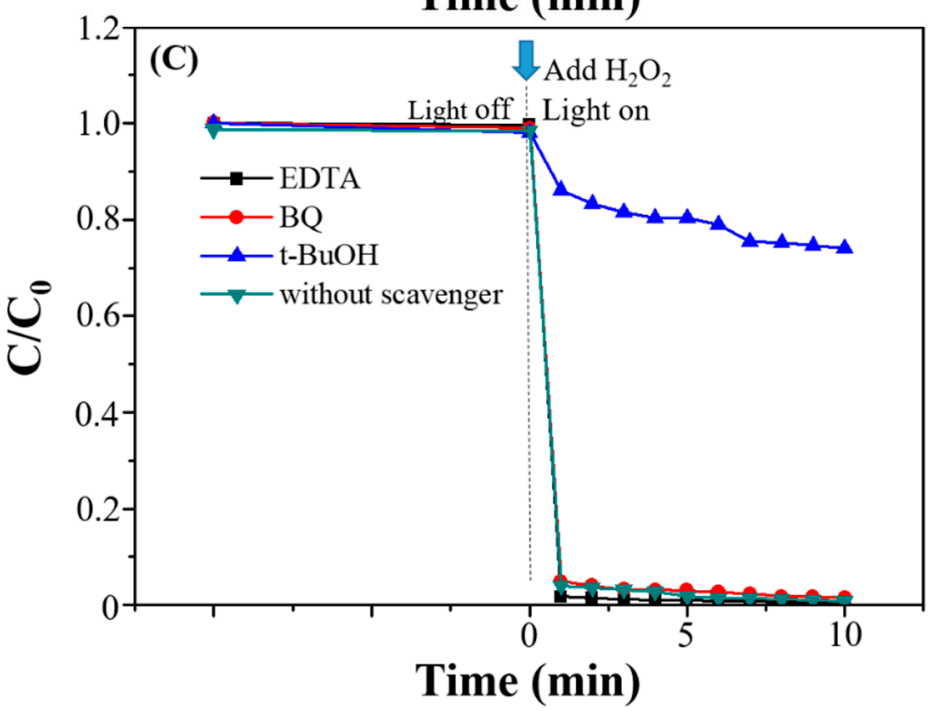

Figure 14. Free radical trapping experiment of (A) $\mathrm{Ag}_{3} \mathrm{PO}_{4},(\mathbf{B}) \mathrm{CuFeS}_{2}$, and (C) $\mathrm{CuFeS}_{2} / \mathrm{Ag}_{3} \mathrm{PO}_{4}$ composites. Ethylenediaminetetraacetate (EDTA), tert-butanol (t-BuOH), and p-benzoquinone (BQ) (each $1 \mathrm{mM}$ ) were scavengers for holes, oxygen radicals, and hydroxyl radicals, respectively. 
Hydroxyl radical production was further detected using the fluorescent luminescence (FL) technique to study the photo-Fenton reaction. The FL emission spectra, excited at $370 \mathrm{~nm}$ in the coumarin solution in the absence and presence of the prepared samples, were evaluated for $10 \mathrm{~min}$ of irradiation. Figure 15 shows that an FL signal was observed at $460 \mathrm{~nm}$ for each sample and that the maximum FL intensity was observed in $\mathrm{CuFeS} / \mathrm{Ag}_{3} \mathrm{PO}_{4}$. This suggests that $\mathrm{CuFeS} / \mathrm{Ag}_{3} \mathrm{PO}_{4}$ produced the highest amount of hydroxyl radicals among these three materials, thereby leading to more chemical reactions with coumarin to generate fluorescence [33]. Hence, the hydroxyl radical was considered the direct reactive oxidation species in the $\mathrm{CuFeS}_{2} / \mathrm{Ag}_{3} \mathrm{PO}_{4}$ composites for RhB degradation. Moreover, $\mathrm{CuFeS} / \mathrm{Ag}_{3} \mathrm{PO}_{4}$ composites with maximal degradation activity produced excess reactive hydroxyl radicals than $\mathrm{CuFeS}_{2}$, which is consistent with the previously discussed results.

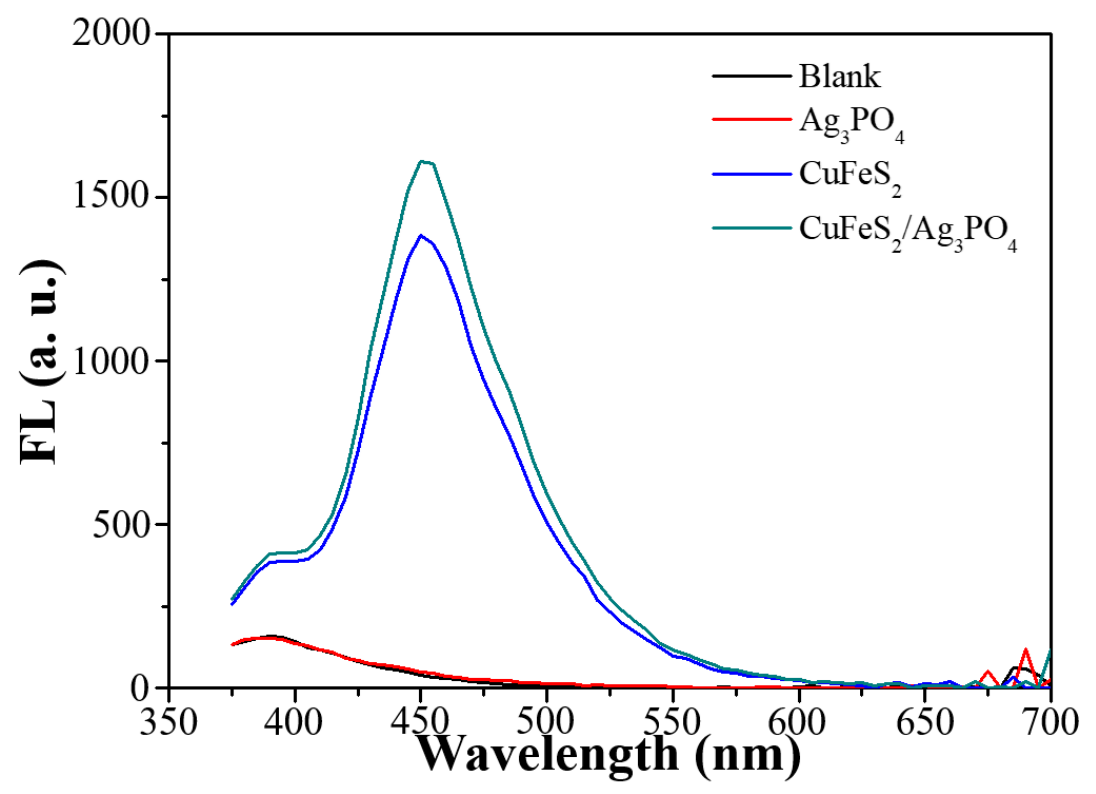

Figure 15. FL spectra of the different samples in the coumarin solution measured at $\lambda_{\mathrm{ex}}=370 \mathrm{~nm}$ (each sample was illuminated for 10 min under visible light). $\mathrm{Ag}_{3} \mathrm{PO}_{4}$ (red), $\mathrm{CuFeS}_{2}$ (blue), and $\mathrm{CuFeS} / \mathrm{Ag}_{3} \mathrm{PO}_{4}$ composites (olive).

On the basis of the results described above, the degradation mechanisms of the $\mathrm{Ag}_{3} \mathrm{PO}_{4}$, $\mathrm{CuFeS}_{2}$, and $\mathrm{CuFeS}_{2} / \mathrm{Ag}_{3} \mathrm{PO}_{4}$ in the photo-Fenton reaction were proposed (Scheme 1). For $\mathrm{Ag}_{3} \mathrm{PO}_{4}$, the electron-hole pairs are generated under LED irradiation (Scheme 1A). The electrons could not form the oxygen radicals because of their higher position in the standard redox potential of oxygen/oxygen radical $(0.13 \mathrm{~V})$ than the $\mathrm{CB}$ potential $(0.27 \mathrm{~V})$. The photogenerated hole can produce the hydroxyl radical because the oxidation potential of the hydroxyl radical $(1.99 \mathrm{~V})$ is lower than the $\mathrm{VB}$ potential of $\mathrm{Ag}_{3} \mathrm{PO}_{4}(2.65 \mathrm{~V})$. However, the recombination rate in $\mathrm{Ag}_{3} \mathrm{PO}_{4}$ is too fast to produce sufficient hydroxyl radicals by the holes. Thus, the holes are responsible for RhB degradation. The poor charge separation of $\mathrm{CuFeS}_{2}$ limits its ability to generate electron-hole pairs, but it is effective in generating hydroxyl radicals through the Fenton reaction (Scheme 1B). However, the Fenton reaction causes an increase in the oxidation state of $\mathrm{Cu}$ and Fe within the $\mathrm{CuFeS}_{2}$ solids, alters the crystal structure, and notably, weakens the integrity of the $\mathrm{CuFeS}_{2}$ solids. This is the main reason $\mathrm{CuFeS}_{2}$ is hardly reused in water treatment. When $\mathrm{Ag}_{3} \mathrm{PO}_{4}$ couples with $\mathrm{CuFeS}_{2}$ to form the $\mathrm{CuFeS} / \mathrm{Ag}_{3} \mathrm{PO}_{4}$ composites, the photogenerated electrons can be easily captured by the oxidized $\mathrm{Fe}^{3+} / \mathrm{Cu}^{2+}$ on the surface of $\mathrm{CuFeS}_{2}$, leading to the regeneration of $\mathrm{Fe}^{2+} / \mathrm{Cu}^{+}$at the $\mathrm{CuFeS}_{2} / \mathrm{Ag}_{3} \mathrm{PO}_{4}$ interface (Scheme $1 \mathrm{C}$ ). As a strong synergistic effect, the formation of hydroxyl radicals through the Fenton reaction on $\mathrm{CuFeS}_{2}$ and photogenerated hole on $\mathrm{Ag}_{3} \mathrm{PO}_{4}$ is favored to enhance the degradation activity and stability of $\mathrm{CuFeS} / \mathrm{Ag}_{3} \mathrm{PO}_{4}$ composites. In addition, we considered that the degradation mechanism for the prepared $\mathrm{Fe}_{2} \mathrm{~S}_{3} / \mathrm{Ag}_{3} \mathrm{PO}_{4}$ and $\mathrm{Cu}_{2} \mathrm{~S} / \mathrm{Ag}_{3} \mathrm{PO}_{4}$ composites was similar to that of $\mathrm{CuFeS} / \mathrm{Ag}_{3} \mathrm{PO}_{4}$ composites. However, the degree 
of the charge separation efficiency, recombination rate of electron-hole pairs and the amount of the major reactive species were slight different, resulting in different degradation performance as shown in Figure 10.

\section{NHE (V)}

(A)

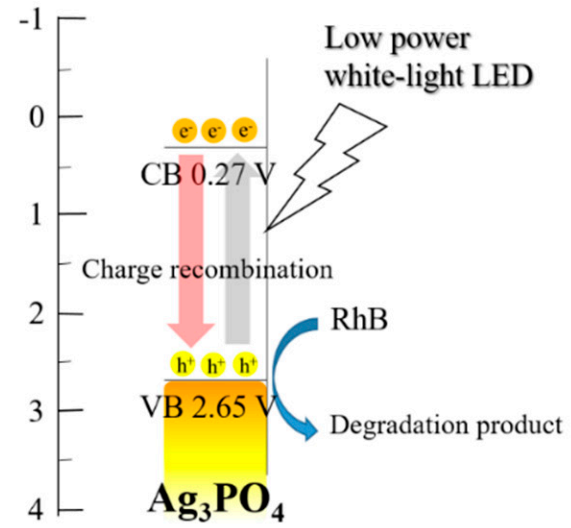

(B)

\section{$\mathrm{CuFeS}_{2}$ surface}

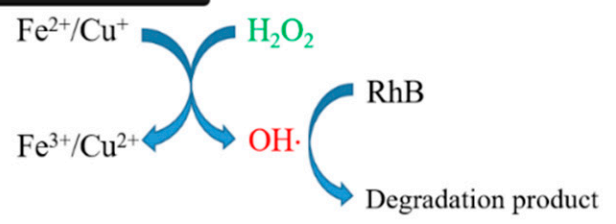

(C)

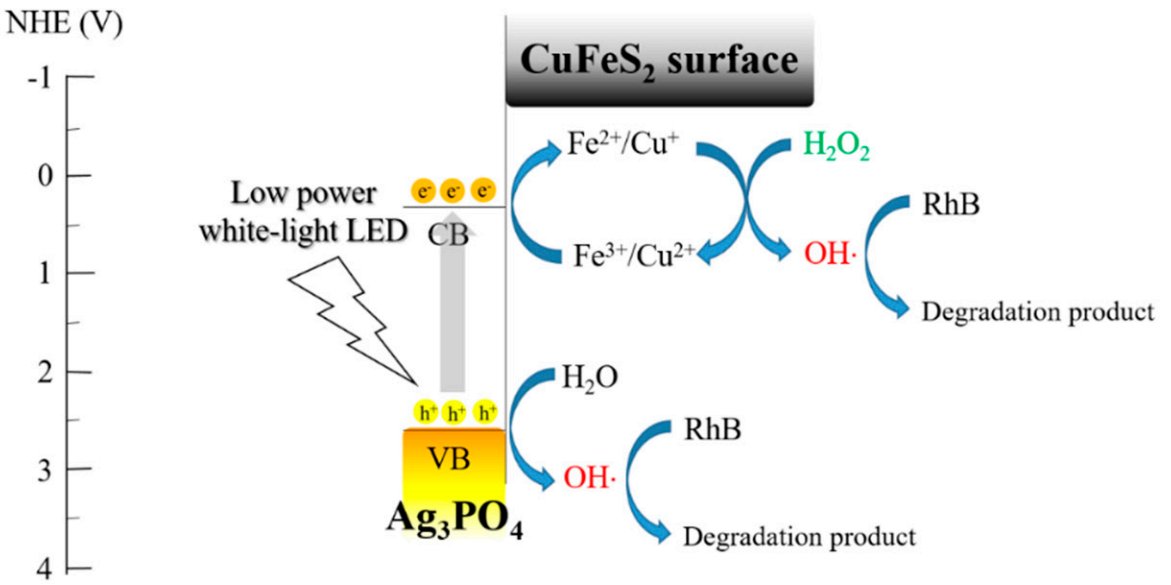

Scheme 1. Transition of electrons and holes in the different degradation system of (A) $\mathrm{Ag}_{3} \mathrm{PO}_{4}$, (B) $\mathrm{CuFeS}_{2}$, and (C) $\mathrm{CuFeS}_{2} / \mathrm{Ag}_{3} \mathrm{PO}_{4}$.

\subsection{Stability and Practical Applications of $\mathrm{CuFeS} / 2 \mathrm{Ag}_{3} \mathrm{PO}_{4}$}

The stability of the catalyst is an essential parameter for the development of practical water treatment applications. To investigate the stability of the prepared $\mathrm{Ag}_{3} \mathrm{PO}_{4}, \mathrm{CuFeS}_{2}$, and $\mathrm{CuFeS}_{2} / \mathrm{Ag}_{3} \mathrm{PO}_{4}$ composites, the results of cyclic $\mathrm{RhB}$ degradation tests were evaluated (shown in Figure 16A); in each cycle, $\mathrm{RhB}$ and $\mathrm{H}_{2} \mathrm{O}_{2}$ were reintroduced into the catalyst. In this study, $\mathrm{RhB}$ degradation by $\mathrm{Ag}_{3} \mathrm{PO}_{4}$ and $\mathrm{CuFeS} / \mathrm{Ag}_{3} \mathrm{PO}_{4}$ after ten cycles maintained a similar degradation efficiency ( $15.3 \%$ to $14 \%$ after ten cycles for $\mathrm{Ag}_{3} \mathrm{PO}_{4} ; 99.6 \%$ to $91.3 \%$ after ten cycles for $\left.\mathrm{CuFeS}_{2} / \mathrm{Ag}_{3} \mathrm{PO}_{4}\right)$, whereas that by $\mathrm{CuFeS}_{2}$ resulted in a considerable loss of efficiency (from $97.5 \%$ to $15.0 \%$ after ten cycles). Furthermore, the corresponding XRD results (Figure 16B) suggest a negligible change in the phase structure of $\mathrm{Ag}_{3} \mathrm{PO}_{4}$ and $\mathrm{CuFeS}_{2} / \mathrm{Ag}_{3} \mathrm{PO}_{4}$ samples after the repeated reactions, indicating the good stability of the samples. However, the initial phase structure of $\mathrm{CuFeS}_{2}$ disappeared after three reaction cycles. The SEM image shown in Figure 16D displays that the morphology of the $\mathrm{CuFeS}_{2}$ sample changed from an irregular sheet to spherical shape, indicating that the Fenton reaction caused structural and chemical change for $\mathrm{CuFeS}_{2}$ when it is used alone. Unlike $\mathrm{CuFeS}_{2}$, the comparison of SEM images for $\mathrm{Ag}_{3} \mathrm{PO}_{4}$ and $\mathrm{CuFeS}_{2} / \mathrm{Ag}_{3} \mathrm{PO}_{4}$ composites before and after reaction cycles only showed a slight change of morphology (Figure 16C,E). Evidently, the stability of $\mathrm{CuFeS}_{2}$ in the 
$\mathrm{CuFeS} / \mathrm{Ag}_{3} \mathrm{PO}_{4}$ composite improved considerably because of its coupling with $\mathrm{Ag}_{3} \mathrm{PO}_{4}$ nanoparticles as the photogenerated electrons in the $\mathrm{CB}$ of $\mathrm{Ag}_{3} \mathrm{PO}_{4}$ reduce $\mathrm{Fe}^{3+} / \mathrm{Cu}^{2+}$ ions and keep them intact in $\mathrm{CuFeS}_{2} / \mathrm{Ag}_{3} \mathrm{PO}_{4}$. This prevented the structural disintegration of $\mathrm{CuFeS}_{2}$ during the Fenton reaction, effectively demonstrating its reusability for catalysis.
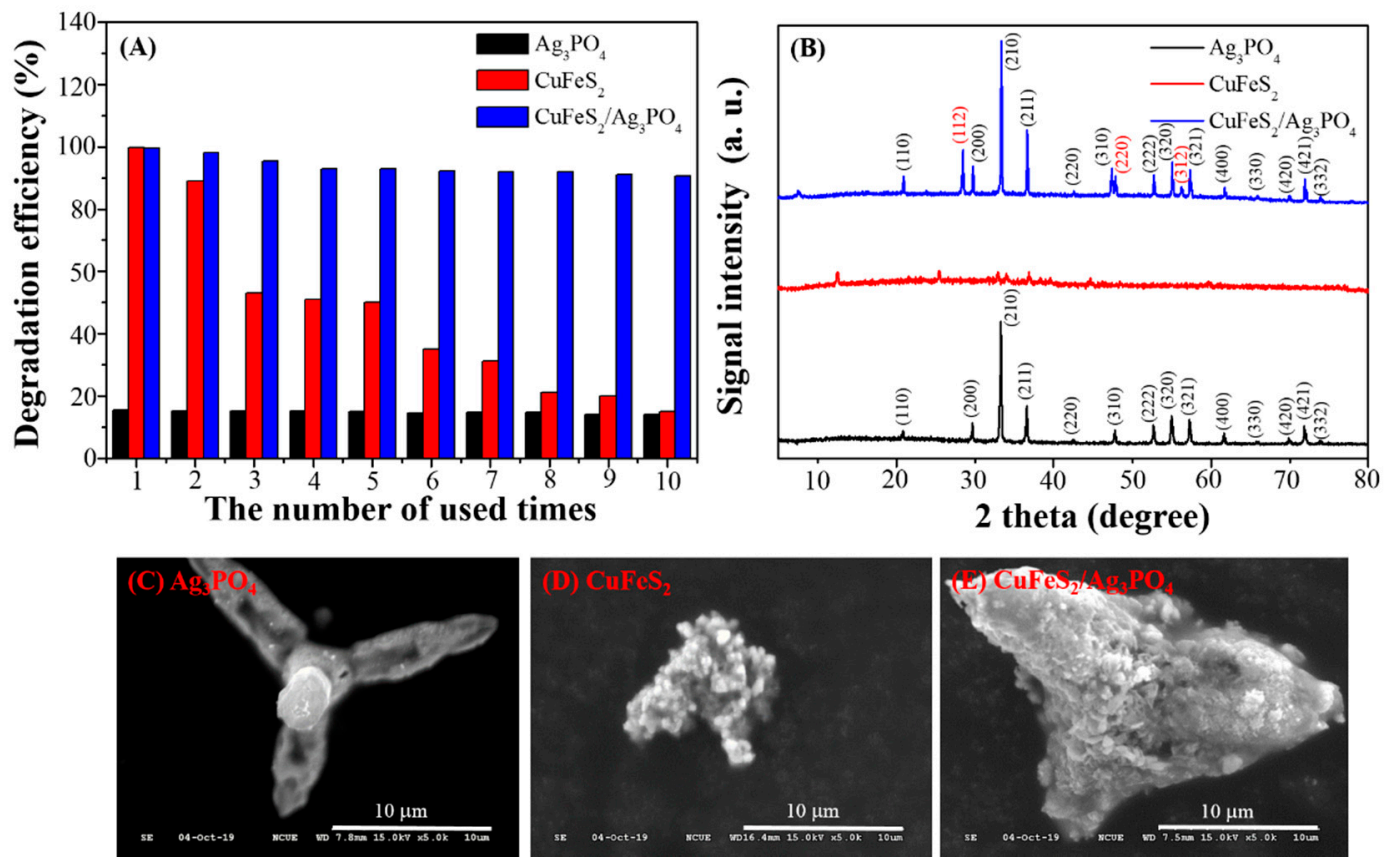

Figure 16. (A) Degradation efficiency under a $10 \mathrm{~min}$ reaction time for the recycle used test, (B) XRD patterns, and (C-E) the corresponding SEM images of the third used samples: $\mathrm{Ag}_{3} \mathrm{PO}_{4}$ (black), $\mathrm{CuFeS}_{2}$ (red), and $\mathrm{CuFeS}_{2} / \mathrm{Ag}_{3} \mathrm{PO}_{4}$ composites (blue).

To assess the practical applications of $\mathrm{CuFeS}_{2} / \mathrm{Ag}_{3} \mathrm{PO}_{4}$, various organic dyes (MR, M6G, fluorescein, and PI) were degraded (Figure 17A). Compared with $\mathrm{TiO}_{2}$ (P25), $\mathrm{CuFeS}_{2} / \mathrm{Ag}_{3} \mathrm{PO}_{4}$ exhibited excellent degradation efficiency toward all selected dyestuffs, with nearly $95 \%$ degradation achieved within $10 \mathrm{~min}$ (except PI with only $78.5 \%$ degradation efficiency). In addition, the degradation performance of $\mathrm{CuFeS}_{2} / \mathrm{Ag}_{3} \mathrm{PO}_{4}$ under sunlight irradiation was evaluated from November to December 2019 from 11:00 a.m. to 2:00 p.m. daily at the National Changhua University of Education, Changhua, Taiwan. As shown in Figure 17B, sunlight-induced RhB degradation in the absence and presence of $\mathrm{CuFeS} 2 / \mathrm{Ag}_{3} \mathrm{PO}_{4}$ was very poor without $\mathrm{H}_{2} \mathrm{O}_{2}$. However, using the sunlight-assisted Fenton reaction for $\mathrm{RhB}$ degradation achieved nearly $98.9 \%$ degradation efficiency within $1 \mathrm{~min}$. This is because the combined UV and visible light in sunlight hastened the production of hydroxyl radicals in the presence of $\mathrm{H}_{2} \mathrm{O}_{2}$ and $\mathrm{CuFeS}_{2} / \mathrm{Ag}_{3} \mathrm{PO}_{4}$. With the promise of the sunlight-assisted Fenton reaction, the $\mathrm{pH}$ effect in the water samples on the degradation performance of $\mathrm{CuFeS} / \mathrm{Ag}_{3} \mathrm{PO}_{4}$ was also investigated. As shown in Figure 17C, the degradation efficiency decreased at $\mathrm{pH} 12.0$ because the Fenton reaction was considerably hindered at a high $\mathrm{pH}$ as $\mathrm{Fe}^{2+}$ cations form inactive porphyrin ferryl complexes $\left(\mathrm{FeO}^{2+}\right)$ in the alkaline solution [24]. Finally, the prepared $\mathrm{CuFeS}_{2} / \mathrm{Ag}_{3} \mathrm{PO}_{4}$ composites were used to degrade $\mathrm{RhB}$ in the environmental water samples (Figure 17D). $\mathrm{CuFeS}_{2} / \mathrm{Ag}_{3} \mathrm{PO}_{4}$ exhibited excellent degradation efficiency through the photo-Fenton reaction for RhB degradation, with nearly $90 \%$ degradation within $1 \mathrm{~min}$. A notable difference in the degradation time for $\mathrm{RhB}$ was observed for the seawater and treated wastewater samples ( $90 \%$ and $80 \%$ degradation within $10 \mathrm{~min}$, respectively) compared with the other environmental water samples $(100 \%$ degradation within $10 \mathrm{~min}$ ) probably because of the presence of anions or radical scavengers in the seawater and treated wastewater samples that reduced the degradation activity of $\mathrm{CuFeS}_{2} / \mathrm{Ag}_{3} \mathrm{PO}_{4}$. Nevertheless, the studies on the environmental water samples 
strongly support the benefits of this newly developed $\mathrm{CuFeS}_{2} / \mathrm{Ag}_{3} \mathrm{PO}_{4}$-based photo-Fenton water treatment option.
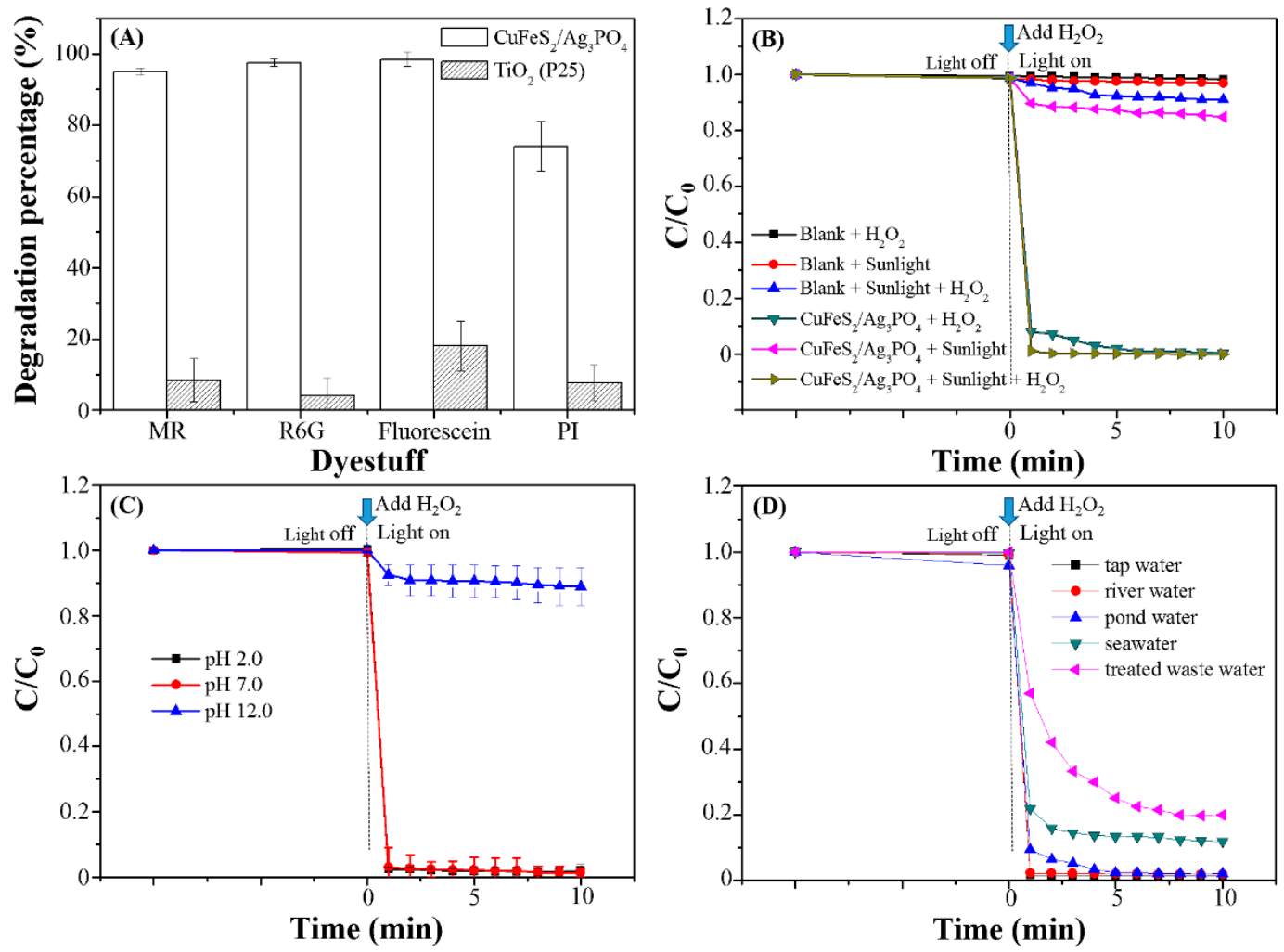

Figure 17. Photo-Fenton reaction of (A) different dyestuff by $\mathrm{CuFeS}_{2} / \mathrm{Ag}_{3} \mathrm{PO}_{4}$ composites and P25; (B) different degradation procedures in the absence and presence of $\mathrm{CuFeS}_{2} / \mathrm{Ag}_{3} \mathrm{PO}_{4}$ under sunlight irradiation; (C) different $\mathrm{pH}$; and (D) different environmental water samples for RhB degradation by $\mathrm{CuFeS}_{2} / \mathrm{Ag}_{3} \mathrm{PO}_{4}$.

\section{Conclusions}

The currently prepared $\mathrm{CuFeS}_{2} / \mathrm{Ag}_{3} \mathrm{PO}_{4}$ composites exhibited higher RhB degradation efficiency through the photo-Fenton reaction than $\operatorname{did} \mathrm{Ag}_{3} \mathrm{PO}_{4}$ and $\mathrm{CuFeS}_{2}$ alone. This high enhancement in the degradation efficiency was attributed to the synergistic effect in material stability and the hydroxyl radical production. The constituent $\mathrm{Ag}_{3} \mathrm{PO}_{4}$ in the newly developed composite not only provides the visible-light absorption ability in degrading organic compounds but also acts as a rich electron source to stabilize the crystal structure of $\mathrm{CuFeS}_{2}$ under light irradiation. Consequently, $\mathrm{Cu}^{2+} / \mathrm{Fe}^{3+}$ ions produced by the Fenton reaction can be reduced and regenerated into $\mathrm{Cu}^{+} / \mathrm{Fe}^{2+}$ ions, and the reactive hydroxyl radicals partially from the photogenerated holes of $\mathrm{Ag}_{3} \mathrm{PO}_{4}$ and predominantly from the Fenton reaction of $\mathrm{CuFeS}_{2}$ can be continuously produced to degrade organic compounds. The $\mathrm{CuFeS}_{2} / \mathrm{Ag}_{3} \mathrm{PO}_{4}$ composite has several attractive features not realized in the other reported photo-Fenton reactions (Table 2). First, the prepared $\mathrm{CuFeS}_{2} / \mathrm{Ag}_{3} \mathrm{PO}_{4}$ composite had $96 \% \mathrm{RhB}$ degradation performance under low-power white LED illumination within $1 \mathrm{~min}$. In addition, various dyestuffs (MR, R6G, fluorescein, and PI) with 95\% degradation efficiency could be achieved. Through sunlight-assisted Fenton reaction, the RhB degradation efficiency was further improved to $98.9 \%$. For the recycling used ability, the $\mathrm{CuFeS}_{2} / \mathrm{Ag}_{2} \mathrm{PO}_{4}$ composite is stable enough to be reused through the input of sustainable energy source. Hence, this study discovered the synergistic catalysis $\mathrm{CuFeS}_{2} / \mathrm{Ag}_{3} \mathrm{PO}_{4}$ and successfully demonstrates the application of the sunlight-assisted Fenton reaction on environmental water samples. The current findings can be used for the applications of advanced oxidation technology in wastewater treatment in the future. 
Table 2. Comparison of the degradation performance and practical applications using the photo-Fenton reaction.

\begin{tabular}{|c|c|c|c|c|c|}
\hline Samples & Preparation & Degradation Performance & Sunlight Irradiation & Target & Ref. \\
\hline Citrate- $-\mathrm{CuFeS}{ }_{2}$ & Microwave heating & $\begin{array}{l}90 \% \text { degradation }(0.2 \text { g catalyst } / 50 \\
\text { ppm BPA) within } 15 \mathrm{~min}(4 \mathrm{~W} \\
\text { fluorescent lamp) }\end{array}$ & 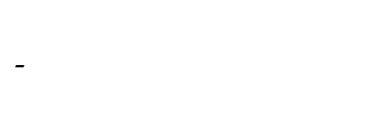 & $\mathrm{BPA}$ & [24] \\
\hline FS- $\mathrm{TiO}_{2}$ disk & Dip-coating method & $\begin{array}{l}\text { 95\% degradation ( } 50 \mathrm{ppm} \text { phenazone } \\
\text { (PNZ)) within } 180 \mathrm{~min} \text { ( } 36 \mathrm{~W} \text { UV light) }\end{array}$ & $\begin{array}{l}95 \% \text { degradation of } 50 \\
\text { ppm PNZ within } 90 \text { min }\end{array}$ & PNZ & {$[34]$} \\
\hline Mined $\mathrm{CuFeS}_{2}$ & Milling process & $\begin{array}{l}85 \% \text { TOC conversion }(1.0 \mathrm{~g} \text { catalyst } / 0.5 \\
\mathrm{mM} \text { tyrosol }(\mathrm{TY})) \text { within } 60 \mathrm{~min}(10 \mathrm{~W} \\
\text { UV LED light) }\end{array}$ & PP & TY & [19] \\
\hline $\mathrm{Fe}-\mathrm{N}-\mathrm{Ag}-\mathrm{TiO}_{2}$ clay bead & $\begin{array}{l}\text { Surface impregnation } \\
\text { method }\end{array}$ & 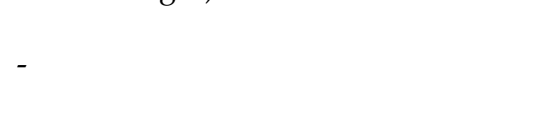 & $\begin{array}{l}77 \% \text { degradation of } 50 \\
\text { ppm cephalexin (CEX) } \\
\text { within } 60 \text { min }\end{array}$ & CEX & [35] \\
\hline $\mathrm{FS} / \mathrm{FA} / \mathrm{TiO}_{2}$ clay bead & Dip-coating method & $\begin{array}{l}89 \% \text { degradation ( } 50 \text { ppm CEX) } \\
\text { within } 4 \text { h ( } 36 \text { W UV light) }\end{array}$ & $\begin{array}{l}94 \% \text { degradation ( } 50 \mathrm{ppm} \\
\mathrm{CEX} \text { ) within } 3.5 \mathrm{~h}\end{array}$ & CEX & [36] \\
\hline $\mathrm{Fe}_{2} \mathrm{O}_{3}-\mathrm{TiO}_{2}$ film & Sol-gel method & $\begin{array}{l}80 \% \text { degradation (10 ppm } \\
\text { ciprofloxacin (CIPRO), } \\
\text { sulfamethoxazole (SMX), and } \\
\text { trimethoprim (TMP) mixture) within } \\
240 \text { min by a solar simulator (Solarbox } \\
\text { Model 1500e) }\end{array}$ & 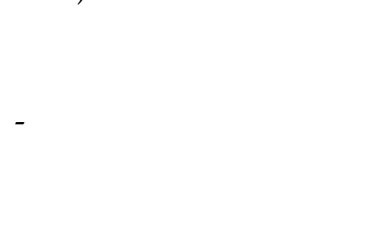 & CIPRO, SMX, TMP & [37] \\
\hline $\mathrm{CuFeS} / \mathrm{Ag}_{3} \mathrm{PO}_{4}$ & Cyclic microwave heating & $\begin{array}{l}96 \% \text { degradation }(20 \mathrm{mg} \text { catalyst } / 20 \\
\text { ppm RhB) within } 1 \mathrm{~min}(2.5 \mathrm{~W} \\
\text { white-light LED) }\end{array}$ & $\begin{array}{l}99.8 \% \text { degradation }(0.15 \mathrm{~g} \\
\text { catalyst } / 15 \mathrm{ppm} \mathrm{MB}) \\
\text { within } 6 \mathrm{~min}\end{array}$ & $\begin{array}{l}\text { RhB, MR, R6G, } \\
\text { Fluorescein, PI, phenol }\end{array}$ & This study \\
\hline
\end{tabular}


Author Contributions: Conceptualization, S.-A.C. and Y.-W.L.; methodology, Y.-W.L.; software, Y.-W.L.; validation, S.-A.C., and T.W.; formal analysis, S.-A.C. and Y.-W.L.; investigation, S.-A.C.; resources, Y.-W.L.; data curation, S.-A.C. and P.-Y.W.; writing-original draft preparation, Y.-W.L.; writing-review and editing, T.W. and Y.-W.L.; visualization, Y.-W.L.; supervision, Y.-W.L.; project administration, Y.-W.L.; funding acquisition, Y.-W.L. All authors have read and agreed to the published version of the manuscript.

Funding: This study was supported by the Ministry of Science and Technology of Taiwan under contract (MOST 109-2113-M-018-002).

Conflicts of Interest: The authors declare no conflict of interest.

\section{References}

1. Fernandez-Llamazares, A.; Garteizgogeascoa, M.; Basu, N.; Brondizio, E.S.; Cabeza, M.; Martinez-Alier, J.; McElwee, P.; Reyes-Garcia, V. A state-of-the-art review of indigenous peoples and environmental pollution. Integr. Environ. Assess. Manag. 2020, 16, 324-341. [CrossRef] [PubMed]

2. Kurwadkar, S. Occurrence and distribution of organic and inorganic pollutants in groundwater. Water Environ. Res. 2019, 91, 1001-1008. [CrossRef] [PubMed]

3. Rasheed, T.; Bilal, M.; Nabeel, F.; Adeel, M.; Iqbal, H.M.N. Environmentally-related contaminants of high concern: Potential sources and analytical modalities for detection, quantification, and treatment. Environ. Int. 2019, 122, 52-66. [CrossRef] [PubMed]

4. Muszynski, P.; Brodowska, M.S.; Paszko, T. Occurrence and transformation of phenoxy acids in aquatic environment and photochemical methods of their removal: A review. Environ. Sci. Pollut. Res. 2020, 27, 1276-1293. [CrossRef] [PubMed]

5. Taghipour, S.; Hosseini, S.M.; Ataie-Ashtiani, B. Engineering nanomaterials for water and wastewater treatment: Review of classifications, properties and applications. New J. Chem. 2019, 43, 7902-7927. [CrossRef]

6. Javaid, R.; Qazi, U.Y. Catalytic oxidation process for the degradation of synthetic dyes: An overview. Int. J. Environ. Res. Public Health 2019, 16, 2066. [CrossRef]

7. Singh, P.; Borthakur, A. A review on biodegradation and photocatalytic degradation of organic pollutants: A bibliometric and comparative analysis. J. Clean Prod. 2018, 196, 1669-1680. [CrossRef]

8. Wang, J.M.; Shih, Y.E.; Wang, P.Y.; Yu, Y.H.; Su, J.F.; Huang, C.P. Hazardous waste treatment technologies. Water Environ. Res. 2019, 91, 1177-1198. [CrossRef]

9. Riaz, S.; Park, S.J. An overview of $\mathrm{TiO}_{2}$-based photocatalytic membrane reactors for water and wastewater treatments. J. Ind. Eng. Chem. 2020, 84, 23-41. [CrossRef]

10. Al-Mamun, M.R.; Kader, S.; Islam, M.S.; Khan, M.Z.H. Photocatalytic activity improvement and application of $\mathrm{UV}_{-\mathrm{TiO}}$ photocatalysis in textile wastewater treatment: A review. J. Environ. Chem. Eng. 2019, 7, 103248. [CrossRef]

11. Kanan, S.; Moyet, M.A.; Arthur, R.B.; Patterson, H.H. Recent advances on $\mathrm{TiO}_{2}$-based photocatalysts toward the degradation of pesticides and major organic pollutants from water bodies. Catal. Rev. Sci. Eng. 2020, 62, 1-65. [CrossRef]

12. Tsang, C.H.A.; Li, K.; Zeng, Y.X.; Zhao, W.; Zhang, T.; Zhan, Y.J.; Xie, R.J.; Leung, D.Y.C.; Huang, H.B. Titanium oxide based photocatalytic materials development and their role of in the air pollutants degradation: Overview and forecast. Environ. Int. 2019, 125, 200-228. [CrossRef] [PubMed]

13. Wetchakun, K.; Wetchakun, N.; Sakulsermsuk, S. An overview of solar/visible light-driven heterogeneous photocatalysis for water purification: $\mathrm{TiO}_{2}$ - and $\mathrm{ZnO}$-based photocatalysts used in suspension photoreactors. J. Ind. Eng. Chem. 2019, 71, 19-49. [CrossRef]

14. Morales, M.A.; Fernandez-Cervantes, I.; Agustin-Serrano, R.; Ruiz-Salgado, S.; Sampedro, M.P.; Varela-Caselis, J.L.; Portillo, R.; Rubio, E. $\mathrm{Ag}_{3} \mathrm{PO}_{4}$ microcrystals with complex polyhedral morphologies diversity obtained by microwave-hydrothermal synthesis for MB degradation under sunlight. Results Phys. 2019, 12, 1344-1356. [CrossRef]

15. Zhang, J.; Liu, X.; Liu, Q.W.; Licao, Y.Q.; Liu, G.D.; Shi, X.H. Z-scheme AgSCN/Ag $\mathrm{PO}_{4} / \mathrm{C}_{3} \mathrm{~N}_{4}$ heterojunction with excellent photocatalytic degradation of ibuprofen. Ceram. Int. 2020, 46, 106-113. [CrossRef]

16. Ge, M.; Li, Z.L. Recent progress in $\mathrm{Ag}_{3} \mathrm{PO}_{4}$-based all-solid-state Z-scheme photocatalytic systems. Chin. J. Catal. 2017, 38, 1794-1803. [CrossRef] 
17. Bi, Z.H.; Li, Z.H.; Yan, L.F. Catalytic oxidation of lignin to dicarboxylic acid over the $\mathrm{CuFeS}_{2}$ nanoparticle catalyst. Green Process. Synth. 2018, 7, 306-315. [CrossRef]

18. Labiadh, L.; Ammar, S.; Karnali, A.R. Oxidation/mineralization of AO7 by electro-Fenton process using chalcopyrite as the heterogeneous source of iron and copper catalysts with enhanced degradation activity and reusability. J. Electroanal. Chem. 2019, 853, 113532. [CrossRef]

19. Ltaief, A.H.; Pastrana-Martinez, L.M.; Ammar, S.; Gadri, A.; Faria, J.L.; Silva, A.M.T. Mined pyrite and chalcopyrite as catalysts for spontaneous acidic $\mathrm{pH}$ adjustment in Fenton and LED photo-Fenton-like processes. J. Chem. Technol. Biotechnol. 2018, 93, 1137-1146. [CrossRef]

20. Nie, W.S.; Mao, Q.H.; Ding, Y.B.; Hu, Y.; Tang, H.Q. Highly efficient catalysis of chalcopyrite with surface bonded ferrous species for activation of peroxymonosulfate toward degradation of bisphenol A: A mechanism study. J. Hazard. Mater. 2019, 364, 59-68. [CrossRef]

21. Xu, X.J.; Tang, D.D.; Cai, J.H.; Xi, B.D.; Zhang, Y.; Pi, L.; Mao, X.H. Heterogeneous activation of peroxymonocarbonate by chalcopyrite $\left(\mathrm{CuFeS}_{2}\right)$ for efficient degradation of 2,4-dichlorophenol in simulated groundwater. Appl. Catal. B Environ. 2019, 251, 273-282. [CrossRef]

22. Zhu, Y.P.; Zhu, R.L.; Xi, Y.F.; Zhu, J.X.; Zhu, G.Q.; He, H.P. Strategies for enhancing the heterogeneous Fenton catalytic reactivity: A review. Appl. Catal. B Environ. 2019, 255, 117739. [CrossRef]

23. Zhang, M.H.; Dong, H.; Zhao, L.; Wang, D.X.; Meng, D. A review on Fenton process for organic wastewater treatment based on optimization perspective. Sci. Total Environ. 2019, 670, 110-121. [CrossRef] [PubMed]

24. Salla, J.D.; Martinello, K.D.; Dotto, G.L.; Garcia-Diaz, E.; Javed, H.; Alvarez, P.J.J.; Foletto, E.L. Synthesis of citrate-modified $\mathrm{CuFeS}_{2}$ catalyst with significant effect on the photo-Fenton degradation efficiency of bisphenol a under visible light and near-neutral pH. Colloid Surf. A Physicochem. Eng. Asp. 2020, 595, 124679. [CrossRef]

25. Zhang, J.B.; Sun, X.H.; Gao, Q.J.; Wang, H.X.; Liang, D.X.; Liu, Z.M.; Han, G.T.; Jiang, W. Degradation of organic dyes over regenerative $\mathrm{Fe}_{3} \mathrm{O}_{4} / \mathrm{CuFeS}_{2} /$ biomass composite column. Chem. J. Chin. Univ. Chin. 2019, 40, 425-430.

26. Wei, T.T.; Wu, T.; Lin, Y.W. Controlled synthesis of $\mathrm{Ag}_{3} \mathrm{PO}_{4}$ microparticles with different morphologies and their photocatalytic degradation of rhodamine B under white light-emitting diode irradiation. Micro Nano Lett. 2019, 14, 363-366. [CrossRef]

27. Rajaji, U.; Murugan, K.; Chen, S.M.; Govindasamy, M.; Chen, T.W.; Lin, P.H.; Prabha, P.L. Graphene oxide encapsulated 3D porous chalcopyrite $\left(\mathrm{CuFeS}_{2}\right)$ nanocomposite as an emerging electrocatalyst for agro-hazardous (methyl paraoxon) detection in vegetables. Compos. Part B Eng. 2019, 160, 268-276. [CrossRef]

28. Wang, C.Y.; Wu, T.H.; Lin, Y.W. Preparation and characterization of bismuth oxychloride/reduced graphene oxide for photocatalytic degradation of rhodamine B under white-light light-emitting-diode and sunlight irradiation. J. Photochem. Photobiol. A Chem. 2019, 371, 355-364. [CrossRef]

29. Huang, C.W.; Wu, M.Y.; Lin, Y.W. Solvothermal synthesis of Ag hybrid $\mathrm{BiPO}_{4}$ heterostructures with enhanced photodegradation activity and stability. J. Colloid Interface Sci. 2017, 490, 217-225. [CrossRef]

30. Huang, C.K.; Wu, T.; Huang, C.W.; Lai, C.Y.; Wu, M.Y.; Lin, Y.W. Enhanced photocatalytic performance of $\mathrm{BiVO}_{4}$ in aqueous $\mathrm{AgNO}_{3}$ solution under visible light irradiation. Appl. Surf. Sci. 2017, 399, 10-19. [CrossRef]

31. Hu, X.F.; Mohamood, T.; Ma, W.H.; Chen, C.C.; Zhao, J.C. Oxidative decomposition of rhodamine B dye in the presence of $\mathrm{VO}^{2+}$ and/or $\mathrm{Pt}(\mathrm{IV})$ under visible light irradiation: N-deethylation, chromophore cleavage, and mineralization. J. Phys. Chem. B 2006, 110, 26012-26018. [CrossRef] [PubMed]

32. Qu, P.; Zhao, J.C.; Shen, T.; Hidaka, H. TiO 2 -assisted photodegradation of dyes: A study of two competitive primary processes in the degradation of $\mathrm{RB}$ in an aqueous $\mathrm{TiO}_{2}$ colloidal solution. J. Mol. Catal. A Chem. 1998, 129, 257-268. [CrossRef]

33. Huang, T.Y.; Chen, Y.J.; Lai, C.Y.; Lin, Y.W. Synthesis, characterization, enhanced sunlight photocatalytic properties, and stability of $\mathrm{Ag} / \mathrm{Ag}_{3} \mathrm{PO}_{4}$ nanostructure-sensitized $\mathrm{BiPO}_{4}$. RSC Adv. 2015, 5, 43854-43862. [CrossRef]

34. Bansal, P.; Verma, A.; Mehta, C.; Sangal, V.K. Potential use of waste foundry sand in dual process (photocatalysis and photo-Fenton) for the effective removal of phenazone from water: Slurry and fixed-bed approach. J. Environ. Manag. 2019, 233, 793-801. [CrossRef] [PubMed] 
35. Bansal, P.; Verma, A. N, Ag co-doped $\mathrm{TiO}_{2}$ mediated modified in-situ dual process (modified photocatalysis and photo-Fenton) in fixed-mode for the degradation of Cephalexin under solar irradiations. Chemosphere 2018, 212, 611-619. [CrossRef] [PubMed]

36. Bansal, P.; Verma, A. Synergistic effect of dual process (photocatalysis and photo-Fenton) for the degradation of Cephalexin using $\mathrm{TiO}_{2}$ immobilized novel clay beads with waste fly ash/foundry sand. J. Photochem. Photobiol. A Chem. 2017, 342, 131-142. [CrossRef]

37. Lima, M.J.; Silva, C.G.; Silva, A.M.T.; Lopes, J.C.B.; Dias, M.M.; Faria, J.L. Homogeneous and heterogeneous photo-Fenton degradation of antibiotics using an innovative static mixer photoreactor. Chem. Eng. J. 2017, 310, 342-351. [CrossRef]

Publisher's Note: MDPI stays neutral with regard to jurisdictional claims in published maps and institutional affiliations.

(C) 2020 by the authors. Licensee MDPI, Basel, Switzerland. This article is an open access article distributed under the terms and conditions of the Creative Commons Attribution (CC BY) license (http://creativecommons.org/licenses/by/4.0/). 